Wei, M., Fan, Y., Luo, L., \& Flamant, G. (2015). Fluid flow distribution optimization for minimizing the peak temperature of a tubular solar receiver. Energy, 91, 663-677. https://doi.org/10.1016/j.energy.2015.08.072

\title{
Fluid Flow Distribution Optimization for Minimizing the Peak Temperature of a Tubular Solar Receiver
}

\author{
Min WEI ${ }^{\mathrm{a}}$, Yilin FAN ${ }^{\mathrm{a}}$, Lingai LUO ${ }^{\mathrm{a}}$, Gilles FLAMANT ${ }^{\mathrm{b}}$ \\ ${ }^{a}$ Laboratoire de Thermocinétique de Nantes, UMR CNRS 6607, Polytech' Nantes - \\ Université de Nantes, La Chantrerie, Rue Christian Pauc, BP 50609, 44306 Nantes Cedex 03, \\ France \\ ${ }^{b}$ Laboratoire Matériaux, Procédés et Energie Solaire (PROMES), UPR CNRS 8521, 7 rue du \\ Four Solaire, 66120 Font-Romeu Odeillo, France
}

\begin{abstract}
High temperature solar receiver is a core component of solar thermal power plants. However, non-uniform solar irradiation on the receiver walls and flow maldistribution of heat transfer fluid inside the tubes may cause the excessive peak temperature, consequently leading to the reduced lifetime. This paper presents an original CFD-based evolutionary algorithm to determine the optimal fluid distribution in a tubular solar receiver for the minimization of its peak temperature. A pressurized-air solar receiver comprising of 45 parallel tubes subjected to a Gaussian-shape net heat flux absorbed by the receiver is used for study. Two optimality criteria are used for the algorithm: identical outlet fluid temperatures and identical temperatures on the centerline of the heated surface. The influences of different filling materials and thermal contact resistances on the optimal fluid distribution and on the peak temperature reduction are also evaluated and discussed.

Results show that the fluid distribution optimization using the algorithm could minimize the peak temperature of the receiver under the optimality criterion of identical temperatures on the centerline. Different shapes of optimal fluid distribution are determined for various filling materials. Cheap material with low thermal conductivity can also meet the peak temperature threshold through optimizing the fluid distribution.
\end{abstract}

Keywords: Flow maldistribution; High temperature solar receiver; Peak temperature; Evolutionary algorithm; Optimality criterion

\footnotetext{
*Corresponding author. Tel.: +33 240683167; Fax: +33 240683141. E-mail address: lingai.luo@univ-nantes.fr
} 


\section{Introduction}

Concentrated Solar Power (CSP) plants are expected to play an important role in the energetic scenarios for more efficient use of renewable energy and for the reduced emission of greenhouse gases $[1,2]$. It is estimated that the CSP would contribute up to $11 \%$ of the global electricity production in year 2050 [3, 4].

In a CSP tower plant, the high temperature solar receiver installed at the top of the tower absorbs and transforms the concentrated solar irradiation delivered from heliostats into heat and then transfers it to a heat transfer fluid. The amount of heat carried by the heat transfer fluid will be used in a downstream thermodynamic cycle to allow electricity generation. The solar receiver, being a key component of CSP systems accounting for about $15 \%$ of the total investment [5], has a decisive influence on the overall efficiency of the plant.

Depending on the geometrical configuration, the solar receivers can be classified into different types, such as volumetric receiver, cavity receiver or particle receiver [6]. In particular, tubular receivers are widely used in present commercial CSP projects because they belong to a proven technology on concepts from heat exchanger which is relatively inexpensive and durable [7,8]. Some numerical or experimental studies on tubular solar receivers in the recent literature are summarized in Table 1. Pressurized air or molten salt are used as heat transfer fluid whereas the receiver is usually made of stainless steel or Inconel.

Table 1. Some recent studies on tubular solar receiver (N: numerical study; E: experimental study).

The lifetime of tubular solar receivers depends strongly on the thermal-mechanical stress on the material which is in close relation with the peak temperature of the receiver wall [18]. Based on the study of [19] on a pressurized-air solar receiver tube made of Alloy 617, the lifetime is estimated about 30 years while operating 10 hours per day under peak temperature of $1100 \mathrm{~K}$. This temperature is also considered as the threshold temperature under which the corresponding mechanical stress reaches the allowable design value that the material can afford for normal operation. When peak wall temperature reaches $1250 \mathrm{~K}$, the real mechanical stress is 7.2 times the allowable design stress, resulting in a reduction of receiver lifetime by a factor of 10 to 20 . Moreover, a peak wall temperature of $1250 \mathrm{~K}$ instead of $1100 \mathrm{~K}$ increases about $40 \%$ the thermal loss due to radiation, leading to more than $3 \%$ reduction in electricity production. Therefore, how to decrease the peak temperature on the solar receiver wall is becoming a serious concern.

The temperature distribution on the tubular solar receiver wall of a given geometry mainly depends on the following factors.

- The material of the receiver: temperature and pressure-resisting materials with high thermal conductivity are generally expected, but often require additional investment cost and technology breakthrough on fabrication methods;

- The power and distribution of concentrated solar irradiation: uniform heat flux on the receiver aperture is often assumed in theoretical analysis, but in reality very difficult to achieve due to the large size of the receiver even with advanced aiming point strategy $[18,20]$. The actual heat flux distribution is generally non-uniform, either similar to a Gaussian shape (e.g. Fig. 3) or to an alternative shape such as "table-top" distribution [12]; 
- The physical properties and the working conditions of heat transfer fluid: this is usually determined by operational specifications of CSP plants;

- And finally the flow distribution of heat transfer fluid among the multiple parallel tubes: this factor is relatively easier to be managed, but may play an important role on reducing the peak temperature of the receiver wall.

Most of the studies in the literature aimed at uniformly distributing the heat transfer fluid among parallel tubes under an assumed uniform solar irradiation. But when the solar irradiation distribution on the receiver wall is in reality non-uniform, there must exist an optimal fluid flow distribution so that the peak temperature of the receiver can be minimized. Then the challenge is how to determine this optimal fluid flow distribution. Researches in this area are relatively fewer and less recognized, with the exception of [12].

In their work [12], an optimality criterion was proposed, suggesting that the peak temperature can be largely reduced when the outlet fluid temperatures from parallel tubes are identical. The theoretical fluid distribution for a single-layer tubular solar receiver could then be determined based on a 1-D heat transfer model, using classic correlations for heat transfer and fluid flow. Various improved receiver designs were also proposed, including multi-diameter or multi-pass configurations. Nevertheless, the analytical solution obtained was more or less approximate because of various simplifications made for the model, i.e. negligible axial heat conduction, established turbulent flow, negligible entrance effect, etc. When dealing with more complicated geometries (e.g. multiple layers of tubes rather than one layer) or transfer mechanisms (e.g. significant non-uniformity in axial/longitudinal heat flux distribution), the formulation of physical models and the solution could become cumbersome, sometimes even impossible.

So emerges the idea that classic analytical approaches could benefit from modern Computational Fluid Dynamics (CFD) simulation. The main objective of the present study is to develop an original CFD-based evolutionary algorithm for the determination of the optimal fluid flow distribution in a tubular solar receiver subjected to a non-uniform net heat flux, so as to minimize the peak temperature on the receiver wall.

For this purpose, a real 3D pressurized-air solar receiver comprising of 45 parallel straight tubes arranged in three layers will be used as a model for study. By comparison with simple tube bundle design, this tube-in-matrix concept allows a better heat dissipation by conduction inside the receiver $[21,22]$.

We will firstly use "identical outlet fluid temperatures" proposed by [12] as the optimality criterion (OC-I), appropriate for introducing the receiver geometry, for describing basic principles of the evolutionary algorithm, and for illustrating the effectiveness of the algorithm through an actual numerical example. The reduction of the peak temperature through the optimization of fluid flow distribution will be presented and discussed.

Furthermore, a detailed analysis may reveal that such optimality criterion (identical outlet fluid temperatures) does not necessarily mean minimum peak temperature on the receiver wall. So a large section of this article is devoted to proposing a new evolutionary optimality criterion for further reducing the peak temperature, taking the receiver geometry and the physical properties of the material into account. The shapes of optimal fluid distribution, the corresponding minimum peak temperatures for different filling materials and the effect of thermal contact resistances will also be compared and discussed.

It should be emphasized that the present article is focused on the determination of the optimal fluid flow distribution for a tubular solar receiver. The realization of such optimal distribution 
by a simple and practical method is certainly an interesting subject with practical significance, but is beyond the present paper. Some discussions may be found in the perspectives section of the article, in connection to our earlier work on the design and optimization of fluid distributors and collectors [23, 24].

\section{CFD-based Evolutionary Algorithm}

In this section, a 3D multi-layer solar air receiver used as a model for study will be briefly described. The basic principles of the evolutionary algorithm and the CFD simulation parameters will be introduced as well.

\subsection{Geometry of the tubular solar receiver: the tube-in-matrix concept}

Figure 1 shows the geometry of the studied tubular solar receiver, which is a real prototype designed for the PEGASE project [22]. It appears to be a cuboid solid monoblock, the overall dimension being $405 \mathrm{~mm}$ in length ( $z$ direction), $202 \mathrm{~mm}$ in width ( $x$ direction) and $49 \mathrm{~mm}$ in height ( $y$ direction). The inlet fluid distributor and the outlet fluid collector are not included in the present study.

Fig.1. Geometry and dimension of the solar receiver based on tube-in-matrix concept (unit: $\mathrm{mm}$ ).

Figure 1 also shows the sectional view of the A-A plane along the centerline of the upper surface. It may be observed that the solar receiver based on tube-in-matrix concept consists of 3 parts from the outside to the inside: the external shell, the filling material and a bunch of parallel straight tubes. The external shell of the receiver is made of Inconel 600. Inside the external shell are 45 parallel straight tubes $(N=45)$ arranged symmetrically in three aligned layers, each layer having 15 tubes. For the convenience of description, these tubes are indexed by $i$ as layer A to $\mathrm{C}$ from top to bottom, and by $j$ as 1 to 15 from left to right for each layer. The tubes are also made of Inconel 600, with identical geometric dimensions (circular crosssection; inner diameter $d=6 \mathrm{~mm}$ tube length $L=405 \mathrm{~mm}$ ).

The interspaces between the external shell and the tubes are filled with filling materials. Note that various filling materials such as Inconel or copper may be used, aiming at different operating conditions. Inconel 600 is used as the filling material for the first part of the study when "identical outlet fluid temperatures" is selected as the optimality criterion. The influences of different materials on the optimal fluid flow and temperature distributions will also be evaluated and discussed in the latter section.

In actual operation, the upper surface of the shell is irradiated by the concentrated solar power from heliostats. The heat flux received on the heated surface will be transferred through the filling material and the tube walls by conduction, and to the pressurized air (at 15 bar) flowing inside the tubes by convection. Assuming that the solar receiver is well insulated so that there is no heat loss to the environment, i.e. all heat received is transferred to the pressurized air. The following equations can be obtained based on energy and mass conservation.

$$
m^{t o t}=\sum_{i=A}^{C} \sum_{j=1}^{15} m_{i j}
$$


$1 \quad Q^{t o t}=\sum_{i=A}^{C} \sum_{j=1}^{15} Q_{i j}=\sum_{i=A}^{C} \sum_{j=1}^{15} m_{i j}\left(C p_{i j}^{\text {out }} T_{i j}^{\text {out }}-C p_{i j}^{\text {in }} T_{i j}^{\text {in }}\right)$

2

$Q^{\text {tot }}=m^{\text {tot }}\left(\bar{C} p^{\text {out }} \bar{T}^{\text {out }}-\bar{C} p^{\text {in }} \bar{T}^{\text {in }}\right)$

3

4

5

where $m$ is the fluid mass flow-rate, $Q$ the heat transfer rate, $C p$ the specific heat of the fluid and $T$ the fluid temperature. The superscripts tot, in and out stand for total, inlet and outlet, respectively. $\bar{T}^{i n}$ is the identical inlet fluid temperature $\left(\bar{T}^{i n}=T_{i j}^{i n}\right)$ whereas $\bar{T}^{\text {out }}$ is the massaveraged outlet fluid temperature calculated as:

$$
\bar{T}^{\text {out }}=\frac{\sum_{i=1}^{C} \sum_{j=1}^{15} m_{i j} T_{i j}^{o u t}}{m^{\text {tot }}}
$$

\subsection{Basic principle for identical outlet fluid temperature distribution}

The evolutionary algorithm is developed to determine the fluid flow distribution among parallel tubes corresponding to the selected optimality criterion (OC-I: identical outlet fluid temperatures):

$T_{i j}^{\text {out }}=\bar{T}^{\text {out }}$

Since the outlet fluid temperature is directly linked to the mass flow-rate of fluid in the tube, the optimality criterion could be reached by augmenting or reducing the flow-rate in the tubes by comparing $T_{i j}^{\text {out }}$ and $\bar{T}^{\text {out }}$, while keeping the total mass flow-rate $\left(m^{\text {tot }}\right)$ constant. More precisely, if the outlet fluid temperature of the tube $i j$ is lower than the mean value, then the flow-rate of this tube $m_{i j}$ should be reduced. Vice versa if $T_{i j}^{o u t}$ is higher than $\bar{T}^{\text {out }}, m_{i j}$ should be increased to reach a lower outlet fluid temperature. The variation of different $m_{i j}$ according to the difference between $T_{i j}^{\text {out }}$ and $\bar{T}^{\text {out }}$ repeats iteratively until the optimality criterion Eq. (5) is achieved.

Ideally, the increment or decrement of $m_{i j}$ from one optimization step to another should be as small as possible. However, that will by far lengthen the calculation time thus it is not highly efficient. Therefore, we introduce a variation rule as presented in Eq. (6). From $t$ to $t+1$ step, the variation of $m_{i j}$ is proportional to the difference between $T_{i j}^{\text {out }}$ and $\bar{T}^{\text {out }}$ :

$\Delta m_{i j, t}=m_{i j, t+1}-m_{i j, t}=\gamma\left(m_{i j, t} T_{i j, t}^{o u t}-m_{i j, t} \bar{T}^{\text {out }}\right)$

where $\gamma$ is a relaxation factor always larger than zero to control the variation amplitude. Following this rule, the total inlet mass flow-rate is approximately constant during the optimization procedure, with the assumption that the variation of $C p$ is negligible (actually $<2.6 \%$ ) within the range of tested temperature conditions

$$
\sum_{i=A}^{C} \sum_{j=1}^{15} \Delta m_{i j, t}=\gamma \sum_{i=A}^{C} \sum_{j=1}^{15}\left(m_{i j, t} T_{i j, t}^{\text {out }}-m_{i j, t} \bar{T}^{\text {out }}\right)=\gamma\left(\sum_{i=A}^{C} \sum_{j=1}^{15} \frac{Q_{i j, t}}{C p\left(T_{i j, t}^{\text {out }}\right)}-\frac{Q^{\text {tot }}}{C p\left(\bar{T}^{\text {out }}\right)}\right) \approx 0
$$


1 The initial value of $\gamma$ is determined as the following:

$2 \gamma=\max \left(i=A, B, C ; j=1,2, \ldots, 15 \| \frac{m_{i j, t=-1}-m_{i j, t=0}}{m_{i j, t=-1} T_{i j, t=-1}^{\text {out }}-m_{i j, t=0} T_{i j, t=0}^{\text {out }}} \mid\right)$

3 The initial fluid flow distribution as the beginning case (step $t=0$ ) could be arbitrary. Here a 4 uniform inlet fluid flow distribution is used. A conventional shape of flow distribution using 5 conventional rectangular or conic inlet/outlet headers is also introduced for comparison (step $6 t=-1$ ), presenting a certain degree of non-uniformity (as shown in Fig. 5).

7 The degree of closeness between the optimized results and the optimality criterion is 8 quantified by the non-uniformity of outlet fluid temperatures $\left(\mathrm{MF}_{\mathrm{T}}\right)$ defined as follows:

$\mathrm{MF}_{\mathrm{T}}=\sqrt{\frac{1}{N-1} \sum_{i=A}^{C} \sum_{j=1}^{15}\left(\frac{T_{i j}^{\text {out }}-\bar{T}^{\text {out }}}{\bar{T}^{\text {out }}}\right)^{2}}$

The optimality criterion (OC-I) is considered to be achieved when values of $\mathrm{MF}_{\mathrm{T}}$ approach 0 . Meanwhile, the non-uniformity of fluid flow $\left(\mathrm{MF}_{\mathrm{f}}\right)$ frequently used $[25,26]$ can be written as:

$\mathrm{MF}_{\mathrm{f}}=\sqrt{\frac{1}{N-1} \sum_{i=A}^{C} \sum_{j=1}^{15}\left(\frac{m_{i j}-\bar{m}}{\bar{m}}\right)^{2}}$

where $\bar{m}$ is the mean mass flow-rate of all tubes:

$\bar{m}=\frac{\sum_{i=A}^{C} \sum_{j=1}^{15} m_{i j}}{N}$

We also define $\Delta p_{\max }$ as the maximum pressure drop among parallel tubes.

\subsection{Implementation of optimization procedure}

The major steps of the CFD-based evolutionary algorithm are schematized in the following flow chart (Fig. 2) and described in detail below.

(1) Input the initial data such as the size and initial geometry of the solar receiver, the general operational conditions (the ambient temperature, operational pressure, net heat flux distribution, etc.) and the physical properties of working fluid (fluid nature, total inlet mass flow-rate, density, viscosity, etc.).

(2) Mesh generation of the whole simulation domain for both fluid and solid zones.

(3) Input an initial inlet fluid flow distribution among parallel tubes, e.g. a uniform flow distribution as the beginning of evolutionary algorithm.

(4) Calculation of the exact flow and temperature fields by solving the Navier-Stokes and heat transfer equations.

(5) Calculation of the quantities mentioned in the optimality criterion (the outlet fluid temperature of each tube); modification of mass flow-rate distribution according to the variation rule of Eq. (5). 
(6) Recalculation of the exact flow and temperature fields to obtain the updated data.

(7) Check the stable tolerance of the evolutionary algorithm. If the tolerance is satisfied, then the evolutionary procedure is considered to be converged. Practically, the optimization process will be terminated when the value of $\mathrm{MF}_{\mathrm{T}}$ becomes less than 0.001. If not so, the procedure goes back to Step 5 for recurrence.

(8) Exportation of results, including the fluid flow distribution, the temperature field, the peak temperature on the heated surface and the maximum pressure drop, etc.

Fig. 2. Flow chart of the evolutionary algorithm.

\subsection{Calculation of flow and temperature fields by CFD method}

An essential step of the evolutionary algorithm is the calculation of exact flow and temperature fields. This generally involves solving Navier-Stokes equations and heat transfer equations by CFD methods. For the fluid zone, the equation for conservation of mass or continuity equation is:

$$
\frac{\partial \rho}{\partial t}+\nabla \cdot(\rho \vec{u})=0
$$

The momentum conservation equation is described by:

$\frac{\partial}{\partial t}(\rho \vec{u})+\nabla \cdot(\rho \vec{u} \vec{u})=-\nabla p+\nabla \cdot(\Pi)+\rho \vec{g}+\vec{F}$

where $\vec{u}$ is the velocity, $p$ is the static pressure, $\rho \vec{g}$ and $\vec{F}$ are the gravitational body force and external body forces, $\Pi$ is the stress tensor given by:

$$
\Pi=\mu\left[\left(\nabla \vec{u}+\nabla \vec{u}^{\mathrm{T}}\right)-\frac{2}{3} \nabla \cdot \vec{u} I\right]
$$

where $\mu$ is the molecular viscosity, $I$ is the unit tensor.

The energy equation is:

$\frac{\partial}{\partial t}(\rho E)+\nabla \cdot(\vec{u}(\rho E+p))=\nabla \cdot(\lambda \nabla T)+\Pi: \nabla \vec{u}+\rho Q_{H}$

where $E$ is the internal energy, $\lambda$ is the thermal conductivity, and $Q_{H}$ includes the heat of chemical reaction, radiation and any other volumetric heat sources. To predict turbulent flow pattern, additional turbulence models should be employed.

For the solid zone, the energy transport equation is:

$\rho C \frac{\partial T}{\partial t}=\nabla \cdot(\lambda \nabla T)+S_{h}$

where $C$ is the specific heat and $S_{h}$ is the heat sources within the solid. 


\subsection{Numerical parameters for CFD simulation}

Meshes were generated using software ICEM (version 12.1) to build up the geometry model of the studied solar receiver. Note that half of the real object was adopted for the purpose of lessening the computational burden because of the symmetric feature for both the simulation domain and the net heat flux distribution. The grid used in this study had 3680940 elements in total, with 1421550 structured hexahedral elements for fluid zone and 2259390 unstructured hexahedral elements for solid zone. Relatively more mesh elements were used for the fluid zone ( $38.6 \%$ grid for $12.9 \%$ volume) since the physical properties of pressurized air are strongly temperature dependent. A grid independence study was conducted to guarantee that the current mesh density used was appropriate and sufficient regarding both accuracy and calculation time.

The working fluid used was pressurized air at 15 bar while the solar receiver manufacturing material was Inconel 600. The physical properties of fluid and solid were considered as temperature dependent, using the polynomial fitting correlations listed in Table 2 . It should be noted that the expansion properties of solid material were ignored in our study.

\section{Table 2. Physical properties of fluid and solid used for simulations [27].}

In this study, 3D fluid flow simulations were performed under steady state with heat transfer, using a commercial code FLUENT (version 12.1.4). The gravity effect was also considered. Standard $k-\varepsilon$ model was used to simulate the potential turbulent flow. For the pressurevelocity coupling, COUPLED method was used. For discretization, standard method was chosen for pressure and first-order upwind differentiation for momentum.

For the fluid zone, the inlet boundary condition was set as mass flow-rate of air at $300 \mathrm{~K}$ normal to the boundary of the inlets. The total inlet mass flow-rate $\left(\mathrm{m}^{\text {tot }}\right)$ of 45 channels was equal to $135 \mathrm{~g} \cdot \mathrm{s}^{-1}$, each tube having an initial mass flow-rate of $3 \mathrm{~g} \cdot \mathrm{s}^{-1}$. Pressure outlet boundary was set for the outlets with the gauge pressure value being zero. All the walls for tubes were defined as non-slip conditions. For the solid zone, a Gaussian heat flux distribution was defined for the upper surface of the solar receiver, as shown in Fig. 3. It should be noted that the heat flux considered here is net heat flux absorbed by the heated surface of the tubular solar receiver. In real operation the heat losses of a solar receiver are dominated by radiation and convection that results in about $15-20 \%$ of the incident solar radiation [28]. The highest heat flux is located at the center of the heated surface, with the heat flux distribution given by the following equation:

$h=650000 e^{-65 r^{2}}$

where $r$ was the distance to the center point, $e$ the base of the natural logarithm (2.71828) and $h$ the local heat flux. The maximum local heat flux was $650 \mathrm{~kW} \cdot \mathrm{m}^{-2}$ and the average heat flux of the whole surface was $284.6 \mathrm{~kW} \cdot \mathrm{m}^{-2}$. Note that this Gaussian-shape distribution is just an example used for the current study. It could be replaced by any other types of distribution without influencing the evolutionary algorithm. Other external walls of the receiver were considered as adiabatic without heat exchange with the environment.

The solution was considered to be converged when (i) the outlet fluid temperature from each tube and the inlet static pressure were constant from one iteration to the next (less than $0.5 \%$ variation), and (ii) the normalized residuals were lower than $10^{-5}$ for all control equations. At 
each optimization step, MATLAB was used to take the computed flow and temperature fields data from FLUENT, to perform calculations of the flow-rate change for each tube according to Eq. (6) and to pass the data required to FLUENT to recalculate the updated flow and temperature fields.

Fig. 3. Gaussian net heat flux $\left(\mathrm{kW} \cdot \mathrm{m}^{-2}\right)$ absorbed by the heated surface of the solar receiver.

\section{Results and discussion}

\subsection{Effectiveness of the evolutionary algorithm}

Figure 4 shows the evolution of various parameters as a function of the optimization step of the evolutionary algorithm, including the non-uniformity of the outlet fluid temperatures $\left(\mathrm{MF}_{\mathrm{T}}\right)$, the peak temperature of the receiver $\left(T_{\text {peak }}\right)$, the non-uniformity for fluid flow distribution $\left(\mathrm{MF}_{\mathrm{f}}\right)$ and the maximum pressure drop $\left(\Delta p_{\max }\right)$ of the receiver. Note that step -1 stands for the aforementioned conventional fluid flow distribution shown in Fig. 5a as reference case introduced for comparison and step 0 represents the uniform fluid flow distribution $\left(3 \mathrm{~g} \cdot \mathrm{s}^{-1}\right.$ in each tube) used as the initial distribution for optimization.

As shown on Fig. 4a, the values of $\mathrm{MF}_{\mathrm{T}}$ are 0.159 for the conventional fluid distribution case (step -1) and 0.140 for the uniform fluid distribution case (step 0). The distribution of outlet fluid temperatures is obviously non-uniform for both cases. When the evolutionary algorithm proceeds from one step to the next, the value of $\mathrm{MF}_{\mathrm{T}}$ decreases rapidly, implying more uniform distribution of outlet fluid temperatures. Finally identical outlet fluid temperatures $\left(\mathrm{MF}_{\mathrm{T}}<0.001\right)$ can be reached after six steps of optimization, showing that the CFD-based evolutionary algorithm is effective and rapid to achieve the selected optimality criterion.

Also shown on Fig. 4a is the evolution of $\mathrm{MF}_{\mathrm{f}}$ as a function of optimization step. The value of $\mathrm{MF}_{\mathrm{f}}$ increases from 0 for the uniform fluid distribution case (step 0 ) to 1.053 for the optimal case (step 6), indicating a less uniform flow distribution with respect to the conventional fluid distribution case (step $-1, M F_{\mathrm{f}}=0.328$ ). The shape of the optimal fluid flow distribution will be shown and discussed later.

It can be observed from Fig. $4 \mathrm{~b}$ that the evolution of $\Delta p_{\max }$ shows a similar trend as that of the $\mathrm{MF}_{\mathrm{f}}$ curve. This is obviously in line with the actual situation since the maximum pressure drop is directly linked to the highest flow-rate of all tubes. As a result, the lowest value of $\Delta p_{\max }(1343.3 \mathrm{~Pa})$ is reached when fluid flow distribution is uniform whereas $\Delta p_{\max }$ increases with the increasing non-uniformity of fluid flow distribution with its highest value of about $7332 \mathrm{~Pa}$.

It can also be observed from Fig. $4 \mathrm{~b}$ that the key parameter of the objective function - the peak temperature $T_{\text {peak }}$ is reduced from $1335.2 \mathrm{~K}$ (step -1) to $1144.7 \mathrm{~K}$ (step 6), i.e. by 190.5 $\mathrm{K}$. Generally, the value of $T_{\text {peak }}$ decreases along with the decreasing $\mathrm{MF}_{\mathrm{T}}$. This observation supports the OC-I proposed by [12] in that the peak temperature of the receiver can be largely reduced when outlet fluid temperatures tend to be identical. One exception is that the $T_{\text {peak }}$ for the uniform fluid distribution case $(1346.1 \mathrm{~K})$ is slightly higher than that of the conventional fluid distribution case $(1335.2 \mathrm{~K})$. This confirms that uniform fluid flow distribution is apparently not the optimal option regarding peak temperature reduction, under the condition of non-uniform net heat flux distribution. 
Fig. 4. Evolution of different parameters as a function of optimization step. (a) non-uniformity of outlet fluid temperatures $\left(\mathrm{MF}_{\mathrm{T}}\right)$ and non-uniformity of fluid flow distribution $\left(\mathrm{MF}_{\mathrm{f}}\right)$; (b) surface peak temperature $\left(T_{\text {peak }}\right)$ and maximum pressure drop $\left(\Delta p_{\max }\right)$.

\subsection{Comparison of three cases}

More details on the fluid flow and thermal characteristics under three different fluid flow distribution cases (conventional distribution, uniform distribution and optimal distribution) are shown on Fig. 5. For conventional and uniform fluid flow distribution cases, the outlet fluid temperatures from the tubes on layer A are significantly higher than those on layers B and $\mathrm{C}$. The reason lies in that layer $\mathrm{A}$ is geometrically the closest to the heated surface so that it absorbs higher amount of heat than other two layers. In order to achieve the optimality criterion of identical outlet fluid temperatures with a fixed total mass flow-rate of air, more fluid flow should be concentrated in tubes on layer A while the fraction for layers B and C should be reduced.

Fig. 5. Fluid flow and thermal characteristics under three different fluid flow distribution cases. (a) fluid flow distribution; (b) outlet fluid temperature distribution; (c) temperature field on the heated surface of the receiver.

The shape of optimal fluid distribution that leads to identical outlet fluid temperatures is presented in Fig. 5a. Obviously it is far from uniform but presents some specific features. Firstly, the flow-rates of tubes in layer A range from $5.9 \mathrm{~g} \cdot \mathrm{s}^{-1}$ to $8.7 \mathrm{~g} \cdot \mathrm{s}^{-1}$, much higher than those in layer B (from $1.04 \mathrm{~g} \cdot \mathrm{s}^{-1}$ to $1.21 \mathrm{~g} \cdot \mathrm{s}^{-1}$ ) and layer C (from $0.57 \mathrm{~g} \cdot \mathrm{s}^{-1}$ to $0.62 \mathrm{~g} \cdot \mathrm{s}^{-1}$ ). Secondly, the fluid flow distribution among the tubes of layer A shows a parabolic shape with the highest flow-rate in the center (tube A8) and the lowest at the corners (tubes A1 and A15). This trend is in close connection to the Gaussian-shape net heat flux distribution, with its focusing point at the center of the heated surface (as shown in Fig. 2). On the contrary, the fluid flow distribution among the tubes of the layer $\mathrm{B}$ or layer $\mathrm{C}$ is relatively much more uniform.

The corresponding temperature fields on the heated surface of solar receiver for three fluid distribution cases are shown in Fig. 5c. A Gaussian-like temperature field can be observed for uniform fluid distribution case, with the hot spot $\left(T_{\text {peak }}=1346.1 \mathrm{~K}\right)$ located at the center and a temperature difference of $961.9 \mathrm{~K}$ between the maximum and the minimum. For the conventional fluid distribution case having the highest mass flow-rates in central tubes (A8, B8, C8, etc. $)$, the hot spots $\left(T_{\text {peak }}=1335.2 \mathrm{~K}\right)$ are no longer located at the center of the heated surface but appear on both sides of the centerline, the max-min temperature difference being $950.0 \mathrm{~K}$. Meanwhile, the optimal fluid distribution case presents a more uniform temperature distribution on the heated surface, with a reduced peak temperature $\left(T_{\text {peak }}\right)$ of $1144.7 \mathrm{~K}$ and a much smaller max-min temperature difference of $773.7 \mathrm{~K}$.

\subsection{Short summary}

The numerical results presented above indicate that under our studied conditions (multi-layer tubular geometry, Inconel 600 material, Gaussian net heat flux and fixed total mass flow-rate of air), the property of fluid flow distribution has a significant influence on the temperature distribution on the heated surface of the solar receiver. By simply arranging the fluid flow distribution in a proper way among the parallel tubes, the peak temperature could be reduced 
by about $200 \mathrm{~K}$. This optimal fluid flow distribution can be easily determined by our CFDbased evolutionary algorithm, using identical outlet fluid temperatures as the optimality criterion.

One may be satisfied with these encouraging results but another question may arise: is the optimality criterion of identical outlet fluid temperatures equivalent to the minimum peak temperature of the heated surface? Note that it is the peak temperature rather than the uniformity of outlet fluid temperature that is the main issue of concern in relation to the lifetime of solar receivers. The answer is perhaps not: the peak temperature is largely reduced but there is no evidence that it achieves the minimum. Then one may ask: can the peak temperature be further reduced by acting on the fluid flow distribution? If yes, could this optimal fluid distribution be determined by the proposed evolutionary algorithm? Furthermore, what will be the effects of fluid flow distribution on the peak temperature reduction when different filling materials are used for the solar receiver? The following section aims at answering these questions by proposing a new evolutionary optimality criterion (OC-II) for the CFD-based evolutionary algorithm.

\section{A new optimality criterion for peak temperature minimization}

By carefully examining the temperature field of the heated surface for the optimal fluid distribution case (Fig. 5c), one may observe that it still shows a Gaussian-like shape with the hot-spot located at the center of the heated surface. The temperature distribution is not uniform along with the $x$ direction of the receiver, i.e. the isothermal lines are not perpendicular to the fluid flow direction. It seems that the peak temperature can be further reduced by concentrating more fluid flow into the central tubes (e.g. A7, A8, A9) while decreasing the flow-rates in tubes on the edge (e.g. A1, A15). In brief, the optimality criterion of identical outlet fluid temperatures (OC-I) does not necessarily lead to the minimum peak temperature. If one aims at minimizing the peak temperature, the optimality criterion used should be modified and the corresponding optimal fluid flow distribution will be differed from that shown in Fig. 5a.

The main motivation of this section is thus to propose a new evolutionary optimality criterion (OC-II) that leads to minimum peak temperature of the heated surface. The corresponding optimal fluid flow distribution can still be determined using the developed CFD-based evolutionary algorithm.

\subsection{Description of the new optimality criterion}

The basic idea is to adjust the fluid flow distribution among the parallel tubes so that isothermal lines on the heated surface are perpendicular to the fluid flow direction. Due to the Gaussian-shape net heat flux distribution, the peak temperature is always located on the centerline of the heated surface. As a result, identical temperatures on the centerline perpendicular to the fluid flow direction may be proposed as the new optimality criterion (OC-II).

Once the new optimality criterion is proposed, the next step is to establish the variation rule for the mass flow-rate in each tube to realize this OC-II. This calls for a detailed analysis on coupled heat transfer and fluid flow to reveal the relationship between the flow-rate change in each channel and the temperature variation on the centerline. To do that, we reduce the 3D multi-layer tubular solar receiver problem into $2 \mathrm{D}$, by selecting the middle cross section (A-A 
plane shown in Fig. 1) as the study plane. Note that at steady state, the mass flow-rate of fluid at different cross-sections (i.e. tube inlet, middle cross-section, tube outlet) of each tube is constant.

The schematic view of the middle cross-section (A-A plane) is shown in Fig. 1. Recall that the tubes are indexed as $i j$ ( $i$ represents layer from $\mathrm{A}$ to $\mathrm{C}$ and $j$ represents the index of column from 1 to 15). The middle cross-section is divided into 15 columns. In each column, there are three tubes of different layers (e.g. tubes A1, B1, C1 in column 1). Figure 6 shows a simplified heat conduction model from the upper line of each column to the inner wall of one tube. We note the mean temperature on the upper line of column $j$ as $\bar{T}_{j}$ and the average temperature of inner wall of tube $i j$ as $T_{i j}$. By using an equivalent distance between the upper line and the inner tube wall (as shown in Fig. 6a), the conduction heat flux for the single solid material condition (Inconel 600) can be written as follows:

$\Phi_{i j}=\frac{\bar{T}_{j}-T_{i j}}{\frac{l_{i j}}{\lambda_{i j}}}$

where $\lambda_{i j}$ is the average thermal conductivity of solid material:

$\lambda_{i j}=\lambda(T)_{T=\frac{\bar{T}_{j}+T_{i j}}{2}}$

Fig. 6. Simplified heat transfer model for the A-A plane: (a) single material; (b) shell and filler.

When different filling materials other than Inconel 600 are used (Fig. 6b), we assume that the solar receiver is perfectly fabricated so that thermal contact resistances at material interfaces are negligible. Then Eq. (24) could be written as:

$\Phi_{i j}=\frac{\bar{T}_{j}-T_{i j}}{\frac{l_{i j, \text { shell }}}{\lambda_{i j, \text { shell }}}+\frac{l_{i j, \text { filler }}}{\lambda_{i j, \text { filler }}}+\frac{l_{i j, \text { wall }}}{\lambda_{i j, \text { wall }}}}$

In order to achieve identical temperatures on the centerline (upper line of the middle crosssection), the mass flow-rate in each tube $m_{i j}$ will be modulated by comparing $\Phi_{i j}$ and the average $\bar{\Phi}$ of tubes. More precisely, if $\Phi_{i j}$ is higher than $\bar{\Phi}$, the mass flow-rate in tube $i j$ should be increased to further enhance the heat transfer. Vice versa if $\Phi_{i j}$ is smaller than $\bar{\Phi}$, the flow-rate in the tube $i j$ should be reduced because of the poor heat transfer potential.

To realize the new optimality criterion step-by-step by the CFD-based evolutionary algorithm, a variation rule is introduced as follows:

$$
\Delta m_{i j, t}=m_{i j, t+1}-m_{i j, t}=\gamma\left(\Phi_{i j}-\bar{\Phi}\right)
$$

where $\gamma$ is the aforementioned relaxation factor in Eq. (7). It should be noted that during the optimization steps, the mass flow-rate in some tubes may approach zero. Therefore the average $\bar{\Phi}$ is calculated as: 
$1 \bar{\Phi}=\frac{\sum_{i=A}^{C} \sum_{j=1}^{15} \Phi_{i j}}{N^{\prime}} \quad\left(\right.$ for $\left.\quad m_{i j}>0\right)$

2 where $N^{\prime}$ is the number of tubes whose flow-rates are not equal to zero.

3 The shape of optimal fluid distribution obtained for identical outlet fluid temperatures (Fig. 5a)

4 is used as the beginning case (step 0) this time. The implementation of the CFD-based

5 evolutionary algorithm is similar as that shown in Fig. 2 and explained in section 2.3. The

6 main distinction is the use of new optimality criterion of identical temperatures on the

7 centerline so that the termination condition of the algorithm is defined as:

$8 \quad \bar{T}_{j}=\overline{\bar{T}} \quad(j=1,2, \ldots, 15)$

9 where $\overline{\bar{T}}$ is the mean temperature of all $15 \bar{T}_{j}$.

$10 \quad \overline{\bar{T}}=\frac{\sum_{j=1}^{15} \bar{T}_{j}}{15}$

11 Practically, we consider that the new optimality criterion is achieved when $\mathrm{MF}_{\overline{\mathrm{T}}_{\mathrm{i}}}$ is less than

0.001 , where $\mathrm{MF}_{\overline{\mathrm{T}}_{\mathrm{j}}}$ is the non-uniformity of $\bar{T}_{j}$ calculated as:

13

$\mathrm{MF}_{\overline{\mathrm{T}}_{\mathrm{j}}}=\sqrt{\frac{1}{14} \sum_{j=1}^{15}\left(\frac{\bar{T}_{j}-\overline{\bar{T}}}{\overline{\bar{T}}}\right)^{2}}$
14

\subsection{Optimization results}

This sub-section presents the optimization results for OC-II when Inconel 600 is used as filling material. The effects of different filling materials will be discussed in the next subsection.

Figure 7 shows the evolution of the non-uniformity of $\bar{T}_{j}\left(\mathrm{MF}_{\overline{\mathrm{T}}_{\mathrm{j}}}\right)$ and the peak temperature ( $\left.T_{\text {peak }}\right)$ of the heated surface as a function of optimization step. It can be observed that the value of $\mathrm{MF}_{\overline{\mathrm{T}}_{\mathrm{j}}}$ decreases from 0.049 (step 0) to less than 0.001 (step 6) during 6 optimization steps, indicating that the temperature distribution on the centerline becomes more and more uniform. The corresponding peak temperature is also reduced from $1144.7 \mathrm{~K}$ (step 0 ) to 1094.0 K (step 6). Compared to the optimality criterion of identical outlet fluid temperatures (OC-I) proposed by [12], the newly proposed OC-II is more effective regarding the peak temperature reduction.

Fig. 7. Evolution of surface peak temperature $\left(T_{\text {peak }}\right)$ and non-uniformity of $\bar{T}_{j}\left(\mathrm{MF}_{\overline{\mathrm{T}}_{\mathrm{j}}}\right)$ as a function of optimization step. 
The optimal fluid flow distribution corresponding to the OC-II is shown in the first row of Fig. 8. It can be observed that the vast majority of mass flow $(97 \%)$ is concentrated in tubes of layer A, showing a parabolic shape with the highest value $\left(11.9 \mathrm{~g} \cdot \mathrm{m}^{-1}\right)$ in the middle (tube A8) and the lowest $\left(4.81 \mathrm{~g} \cdot \mathrm{m}^{-1}\right)$ at the corners (tubes A1 and A15). Several tubes in layer B (B5B11) have a small proportion of mass flow (3\%) ranging from $0.2 \mathrm{~g} \cdot \mathrm{m}^{-1}$ to $0.88 \mathrm{~g} \cdot \mathrm{m}^{-1}$, while tubes in layer $\mathrm{C}$ are totally empty. By comparing Fig. 8a and Fig. 5a, one may find that increasing the mass flow-rate proportion in tubes closer to the heat source could further reduce the peak temperature of the heated surface.

Figure $8 \mathrm{a}$ also shows the corresponding temperature field on the heated surface. It can be observed that the isothermal lines on the heated surface are by and large perpendicular to the direction of fluid flow so that the peak temperature of the heated surface may be considered to be minimized.

Fig. 8. Effects of different filling materials on the optimal fluid distribution (a) and the corresponding temperature field of the heated surface (b)

\subsection{Effect of different filling materials}

From the viewpoint of heat transfer, Inconel 600 may not be that favorable as filling material due to its relatively low thermal conductivity (about $20 \mathrm{~W} \cdot \mathrm{m}^{-1} \cdot \mathrm{K}^{-1}$ ). In order to evaluate the effectiveness of the OC-II and the influence of optimal fluid distribution on peak temperature reduction under different filling material conditions, three filling materials (iron, brass and copper) with higher thermal conductivities are introduced for comparison. The physical proprieties of the studied materials within the tested temperature range used in the CFD simulations are listed in Table 3.

Table 3. Physical proprieties of different filling materials within the tested temperature (K) range [27, 29].

Figure 8 shows the shape of optimal fluid distribution, the corresponding temperature field of the heated surface and the minimum peak temperature for different filling materials. For every filling material, the isothermal lines are all perpendicular to the fluid flow direction, without obvious "hot spots" on the heated surface. This confirms the fact that the new optimality criterion is applicable to various filling materials with different thermal conductivities.

It can also be observed from Fig. 8a that the shape of optimal fluid distribution is greatly differed from one filling material to another. The higher the thermal conductivity of filling material, the higher proportion of mass flow will be shared by the layers far from the heated surface. When copper is used as filling material, the proportion of mass flow-rate for layer A, $\mathrm{B}$ and $\mathrm{C}$ is $35.5 \%, 36.9 \%$ and $27.6 \%$, respectively. Let us notice that for Inconel 600 , these values are $97.0 \%$ (layer A), 3.0\% (layer B) and $0.0 \%$ (layer C). This trend is in line with the smaller thermal resistance for heat conduction when high thermal conductivity filling materials are used. Higher mass flow-rates are thus necessary for tubes in layer B or C to evacuate more heat flux transferred from the heated surface.

The obtained results also indicate that when Inconel 600 is used as filling material, multiplelayer design may not be necessary since tubes in layers B and $\mathrm{C}$ are almost not used. By optimizing the fluid flow distribution under the new optimality criterion, one layer of parallel tubes is sufficient for saving the materials. On the contrary when brass or copper is used as 
filling material, all three layers are useful. One or more additional layers could also be arranged for the receiver design with the purpose of reducing the total pressure drop with the same load.

Figure 9 presents the calculated results of peak temperature $\left(T_{\text {peak }}\right)$ for four filling materials, under different fluid flow distribution conditions, i.e. conventional distribution, uniform distribution, optimal distribution for OC-I and optimal distribution for OC-II. For every filling material, the peak temperature is the lowest when fluid flow distribution is optimized for identical temperatures on the centerline, indicating the effectiveness of the new optimality criterion and the evolutionary algorithm.

Fig. 9. Peak temperature reduction for different filling materials.

It can also be observed from Fig. 9 that the use of filling material with high thermal conductivity could significant reduce the peak temperature than that with low thermal conductivity. The minimum peak temperature decreases from $1094 \mathrm{~K}$ for Inconel 600 , to 946.4 $\mathrm{K}$ for iron, to $830.4 \mathrm{~K}$ for brass and just to $762.8 \mathrm{~K}$ for copper. This implies that filling material with high thermal conductivity (e.g. copper) is much more favorable in practical use regarding peak temperature reduction, but usually requires higher cost. In contrast for simpler assembly using one single refractory alloy with low thermal conductivity (e.g. Inconel 600), the peak temperature of the receiver could be minimized from $1349 \mathrm{~K}$ to $1094 \mathrm{~K}$ (below the threshold value of $1100 \mathrm{~K}$ ) through simply optimizing the fluid flow distribution. In this sense, the efforts of fluid flow distribution optimization seem to be worthwhile regarding lower material cost and easier fabrication.

\subsection{Effect of thermal contact resistance}

In the above analysis, we assumed perfect contacts between different materials in the tubesin-matrix concept so that the thermal contact resistances at materials' interfaces were neglected. However, due to the fabrication process, thermal contact resistances may not be negligible especially for materials with relatively high thermal conductivity. In this section, possible effects of thermal contact resistances on the peak temperature of the receiver and on the optimal shape of flow distribution will be tested and discussed by some additional cases, using copper as the filling material.

In fact, the thermal contact resistances could be easily taken into account in our CFD-based evolutionary algorithm. To do that, additional values of thermal resistance are assigned as boundary condition for interfaces (between the shell and the filling material, and between the filling material and the Inconel tubes) in CFD simulations. For the evolutionary algorithm, an extra term $\left(1 / h_{c}\right)$ should be added in Eq. (26) for representing the global thermal contact resistance:

$$
\Phi_{i j}=\frac{\bar{T}_{j}-T_{i j}}{\frac{l_{i j, \text { shell }}}{\lambda_{i j, \text { shell }}}+\frac{l_{i j, \text { filler }}}{\lambda_{i j, \text { filler }}}+\frac{l_{i j \text {,wall }}}{\lambda_{i j, \text { wall }}}+\frac{1}{h_{c}}}
$$

where $h_{c}$ is the global thermal contact conductance and its reciprocal is the global thermal contact resistance. 
The thermal contact resistance depends on many factors such as the roughness of contact surfaces, the properties of the contacting materials (i.e. hardness, thermal conductivity, etc.), and the operational conditions (i.e. pressure, temperature, etc.). Therefore, the exact values vary widely in different cases and are difficult to be determined. In this study we used the correlation proposed by [30] to make a rough estimation of the order of magnitude:

$$
h_{c}=4200 \lambda_{s} R_{a}^{-0.257}\left(\frac{P}{H}\right)^{0.95}
$$

where $P$ is the contact pressure, $H$ is the surface micro hardness, $R_{a}$ is the combined average roughness and $\lambda_{s}$ is the harmonic mean thermal conductivity given by [30]:

$\lambda_{s}=\frac{2 \lambda_{1} \lambda_{2}}{\lambda_{1}+\lambda_{2}}$

where $\lambda_{1}$ and $\lambda_{2}$ are the thermal conductivities of two contacted materials (Inconel and copper). Note that under ideal condition when contacted surfaces are perfectly fabricated and very smooth, the value of $R_{a}$ reaches zero, implying zero thermal contact resistances.

Using proper values for different parameters, the reasonable value of thermal contact resistance between Inconel and copper is estimated in the order of magnitude of $10^{-5} \mathrm{~m}^{2} \cdot \mathrm{K} \cdot \mathrm{W}^{-}$ 1 . Of course this value augments when surface roughness increases or fabrication defects occur. As a result, two values, $1 / h_{c}=1 \times 10^{-5} \mathrm{~m}^{2} \cdot \mathrm{K} \cdot \mathrm{W}^{-1}$ and $1 / h_{c}=1 \times 10^{-4} \mathrm{~m}^{2} \cdot \mathrm{K} \cdot \mathrm{W}^{-1}$, have been tested to represent low and high thermal contact resistance.

The values of receiver's peak temperature under different thermal contact resistances conditions are shown in Table 4. When uniform inlet flow distribution is provided, the $T_{\text {peak }}$ increases slightly from $767.6 \mathrm{~K}\left(1 / h_{c}=0\right)$ to $771.3 \mathrm{~K}\left(1 / h_{c}=1 \times 10^{-5} \mathrm{~m}^{2} \cdot \mathrm{K}^{\prime} \cdot \mathrm{W}^{-1}\right)$ and jumps towards $829.4 \mathrm{~K}\left(1 / h_{c}=1 \times 10^{-4} \mathrm{~m}^{2} \cdot \mathrm{K} \cdot \mathrm{W}^{-1}\right)$. This is logic since extra thermal contact resistances augment the global thermal resistance of the receiver. By performing the proposed evolutionary algorithm under the OC-II, the peak temperature of the receiver can always be minimized. As shown in Table 4, the value of $T_{\text {peak }}$ under optimized flow distribution condition is always lower than that under uniform flow distribution, for the same value of thermal contact resistance. Nevertheless, the reduction of $T_{\text {peak }}$ by optimizing the flow distribution (from $829.4 \mathrm{~K}$ to $821.4 \mathrm{~K}$ ) is less significant compared to the negative effect (from $767.6 \mathrm{~K}$ to $829.4 \mathrm{~K})$ of thermal contact resistances for the highest value of $1 / h_{c}\left(1 \times 10^{-4}\right.$ $\left.\mathrm{m}^{2} \cdot \mathrm{K} \cdot \mathrm{W}^{-1}\right)$.

Table 4. $T_{\text {peak }}$ under different thermal contact resistances

The optimal shapes of flow distribution by considering different thermal contact resistances are shown in Fig. 10. Compared to Fig. 8a for zero thermal contact resistance, it can be observed that the fluid flow slightly shifts to the tubes in layer A and also in the middle of solar receiver. However, the global shape of optimized flow distribution (under OC-II) seems similar.

From the previous results, we can conclude that the proposed evolutionary algorithm can determine the optimal fluid flow distribution for a minimum peak temperature, taking the possible thermal contact resistances into account. For a more precise analysis however, the 
exact values of thermal contact resistance should be experimentally measured rather than rough estimation.

Fig. 10. Optimal fluid flow distribution considering thermal contact resistances (copper as filling material). (a) $1 / h_{c}=1 \times 10^{-5} \mathrm{~m}^{2} \cdot \mathrm{K} \cdot \mathrm{W}^{-1}$; (b) $1 / h_{c}=1 \times 10^{-4} \mathrm{~m}^{2} \cdot \mathrm{K} \cdot \mathrm{W}^{-1}$

\subsection{Discussions}

Compared to the optimality criterion of identical outlet fluid temperatures (OC-I) proposed by [12], the new optimality criterion (OC-II) proposed in this paper is more effective for peak temperature reduction. It is developed for a multiple-layer tubular solar receiver, surely applicable for single-layer designs. In fact a simplified variation rule could be used for a single-layer receiver design by comparing directly the temperatures on the upper line. Eq. (25) could then be modified as:

$$
\Delta m_{j, t}=m_{j, t+1}-m_{j, t}=\gamma\left(\bar{T}_{j}-\overline{\bar{T}}\right)
$$

It should be noted that a Gaussian shape heat flux distribution is assumed in the current study, which is perfectly symmetrical with its focusing point at the center of the heated surface. In reality, the shape of heat flux distribution could be less regular with deviated focusing point [18]. In this case, the studied A-A plane should be adjusted according to the location of the heat flux peak. The new optimality criterion (OC-II) is still applicable in its more general form: identical temperatures on the upper line of the cross-section where the heat flux peak is located.

For the upper heated surface, we used the net heat flux absorbed by the heated surface as the boundary condition for the simulations and optimization to avoid potential influences. But in real operation conditions, the heat losses due to thermal emissions of the heated surface and convection may play an important role on the temperature distribution thus should be carefully considered but may be studied only for a specific solar receiver geometry.

Results also imply that for a multiple-layer design, uniform fluid flow distribution is not the optimal option even when net heat flux is uniform. The proportions of mass flow in tubes from one layer to another will be varied, depending on their distance to the heat source. In other words, uniform fluid distribution is only a special case of optimal solution for uniform net heat flux and single-layer design.

There are of course other advanced numerical optimization methods available for the same objective. One obvious option is brute-force search or exhaustive search, consisting of systematically enumerating all possible fluid flow distributions for the objective function and choosing the best one. Another option is the Genetic Algorithm (GA) that mimicries the natural selection of species to generate useful solution (fluid distribution) to minimize the objective function (peak temperature). Both options are characterized by a poor sensitivity to local minima so that the global best solution can theoretically be proposed. Nevertheless, thousands or even more simulations should be performed for one case study, which make them prohibitive regarding the requirements on calculation time and facilities. In contrast, the CFD-based evolutionary algorithm coupled with the new optimality criterion could propose the optimal solution after a limited number of optimization steps. In this sense, this method is effective, general and flexible. 


\section{Conclusion and perspectives}

In this article, an original CFD-based evolutionary algorithm is developed to determine the optimal fluid flow distribution for minimizing the peak temperature of a multiple-layer tubular solar receiver (tube-in-matrix concept) subjected to non-uniform net heat flux. Two optimality criteria are used and tested, i.e. identical outlet fluid temperatures (OC-I) and identical temperatures on the centerline (OC-II). Different shapes of optimal fluid flow distribution under different filling material conditions are determined and discussed. Based on the numerical results obtained, main conclusions can now be summarized as follows.

- Identical outlet fluid temperatures can be conveniently achieved by performing the evolutionary algorithm. Using this optimality criterion, the peak temperature of the heated surface may be reduced but not be minimized.

- Identical temperatures on the centerline of the heated surface can also be achieved with the evolutionary algorithm. The isothermal lines on the heated surface are byand-large perpendicular to the fluid flow direction, suggesting the minimization of peak temperature.

- The shape of the optimal fluid flow distribution depends strongly on the thermal conductivity of the filling material. The higher the thermal conductivity of filling material, the higher fraction of mass flow should be concentrated in the layer closest to the heated surface, and vice versa. As a result, the number of layers is also a parameter for optimization in solar receiver design.

- Filling material with high thermal conductivity is much more favorable in practical use regarding peak temperature reduction, but often requires higher cost. Moreover, using different filling materials between tubes would raise the question of galvanic action, especially at high temperature. For the purpose of cost saving, manufacturing simplification and ageing resistance, single material with low thermal conductivity can also be used through optimizing the fluid flow distribution, so that the peak temperature could be minimized to be below the threshold value.

- The thermal contact resistances at different interfaces may have a great impact on the peak temperature of the receiver. Thus, the thermal contact resistance should be carefully measured and taken into account in the analysis.

The application fields of the developed evolutionary algorithm are rather vast and promising, and are not limited in CSP solar receivers. It can determine the optimal fluid flow distribution for various engineering equipment or processes, such as for chemical reactors, energy storage systems or heat sinks for cooling of electronic devices. Nevertheless, the objective function should be defined case by case and the corresponding optimality criterion should be well selected.

Once the shape of optimal fluid flow distribution is determined, the next question is how to realize it. This issue involves the novel design of proper fluid distributors/collectors to realize the non-uniform but optimized fluid flow distribution. One practical method is to install a geometrically optimized perforated baffle at the distributing manifold to reach the target flow distribution among downstream parallel channels. Some preliminary work on this subject may be found in the references [23, 24]. A detailed design and optimization of baffled fluid distributor/collector for the multiple-layer solar receiver is a direction of our future work. 
1 It should be noted that the efficiency of the CFD-based evolutionary algorithm depends

2 largely on simulated flow and temperature fields while there is always a departure from the 3 reality. Experimental validation of the evolutionary algorithm using the same tubular solar 4 receiver is our ongoing work.

5

6 Acknowledgement

7 One of the authors M. Min WEI would like to thank the French CNRS and "Région Pays de 8 la Loire" for their financial support to his $\mathrm{PhD}$ study.

9 


\section{Notations}

$\begin{array}{cl}C & \text { specific heat of solid } \\ C p & \text { specific heat of fluid } \\ d & \text { inner diameter of tubes } \\ e & \text { base of the natural logarithm } \\ E & \text { internal energy per unit mass } \\ F & \text { external body force } \\ g & \text { gravitational acceleration } \\ h & \text { heat flux } \\ h_{c} & \text { thermal contact conductance } \\ H & \text { surface microhardness } \\ I & \text { unit tensor } \\ l & \text { equivalent distance between the upper line and the inner tube wall } \\ L & \text { length of tubes } \\ m & \text { fluid mass flow-rate } \\ \text { MF } & \text { maldistribution factor } \\ N & \text { number of parallel straight tubes } \\ p & \text { pressure } \\ P & \text { contact pressure } \\ Q & \text { heat transfer rate } \\ Q_{H} & \text { external heat transfer flux } \\ r & \text { distance to the center point of upper surface } \\ R_{a} & \text { combined average roughness } \\ S_{h} & \text { heat source within the solid } \\ t & \text { time step } \\ T & \text { temperature } \\ u & \text { velocity }\end{array}$

$\mathrm{J} \cdot \mathrm{kg}^{-1} \cdot \mathrm{K}^{-1}$

$\mathrm{J} \cdot \mathrm{kg}^{-1} \cdot \mathrm{K}^{-1}$

$\mathrm{m}$

$\mathrm{J} \cdot \mathrm{kg}^{-1}$

$\mathrm{kg} \cdot \mathrm{m} \cdot \mathrm{s}^{-2}$

$\mathrm{m} \cdot \mathrm{s}^{-2}$

$\mathrm{W} \cdot \mathrm{m}^{-2}$

$\mathrm{W} \cdot \mathrm{m}^{-2} \cdot \mathrm{K}^{-1}$

$\mathrm{Pa}$

m

$\mathrm{m}$

$\mathrm{kg} \cdot \mathrm{s}^{-1}$

$\mathrm{Pa}$

$\mathrm{Pa}$

$\mathrm{W}$

$\mathrm{J} \cdot \mathrm{kg}^{-1} \cdot \mathrm{s}^{-1}$

$\mathrm{m}$

$\mathrm{m}$

$\mathrm{J} \cdot \mathrm{s}^{-1} \cdot \mathrm{m}^{-3}$

$-$

$\mathrm{K}$

$\mathrm{m} \cdot \mathrm{s}^{-1}$

3 Greek symbols

$\gamma$ relaxation factor

$\lambda$ thermal conductivity

$\lambda_{s} \quad$ harmonic mean thermal conductivity

$\mathrm{W} \cdot \mathrm{m}^{-1} \cdot \mathrm{K}^{-1}$

$\mu \quad$ viscosity

$\prod \quad$ stress tensor

$\rho \quad$ density

$\Phi \quad$ conduction heat flux

$\mathrm{W} \cdot \mathrm{m}^{-1} \cdot \mathrm{K}^{-1}$

$\mathrm{kg} \cdot \mathrm{m}^{-1} \cdot \mathrm{s}^{-1}$

$\mathrm{kg} \cdot \mathrm{m}^{-3}$

$\mathrm{W} \cdot \mathrm{m}^{-2}$

\section{Subscripts}

$1,2 \quad$ material index

$f \quad$ fluid

$i, j \quad$ tube index

$\max \quad$ maximum

Superscripts

$\begin{array}{ll}\text { in } & \text { inlet } \\ \text { out } & \text { outlet } \\ \text { tot } & \text { total }\end{array}$




\section{References}

[1] Zaversky, F., Sánchez, M., Astrain, D., 2014. Object-oriented modeling for the transient response simulation of multi-pass shell-and-tube heat exchangers as applied in active indirect thermal energy storage systems for concentrated solar power. Energy, 65, 647-664.

[2] Cocco, D., Serra, F., 2015. Performance comparison of two-tank direct and thermocline thermal energy storage systems for $1 \mathrm{MWe}$ class concentrating solar power plants.Energy, 81, 526-536.

[3] Pitz-Paal, R., Amin, A., Bettzüge, M., Eames, P., Fabrizi, F., Flamant, G., et al., 2013. Concentrating solar power in Europe, the Middle East and North Africa: achieving its potential. Journal of Energy and Power Engineering, 7, 219-228.

[4] IEA, 2014. Technology Roadmap. International Energy Agency. Solar Thermal Electricity, Edition 2014, www.iea.org.

[5] Pitz-Paal, R., Dersch, J., Milow, B., 2003. ECOSTAR-European Concentrated Solar Thermal RoadMapping. Technical Report. Deutsches Zentrum für Luft-und Raumfahrte.V.

[6] Behar, O., Khellaf, A., Mohammedi, K., 2013. A review of studies on central receiver solar thermal power plants. Renewable and Sustainable Energy Reviews, 23, 12-39.

[7] NREL, 2011.Concentrating Solar Power Projects. Retrieved 23rd October, 2012. $<\mathrm{http}: / /$ www.nrel.gov/csp/solarpaces/power_tower.cfm>.

[8] Li, Q., Flamant, G., Yuan, X., Neveu, P., Luo, L., 2011. Compact heat exchangers: A review and future applications for a new generation of high temperature solar receivers. Renewable and Sustainable Energy Reviews, 15, 4855-4875.

[9] Heller, P., Pfänder, M., Denk, T., Tellez, F., Valverde, A., Fernandez, J., et al., 2006. Test and evaluation of a solar powered gas turbine system. Solar Energy, 80, 1225-1230.

[10] Amsbeck, L., Buck, R., Heller, P., Jedamski, J., Uhlig, R., 2008. Development of a tube receiver for a solar-hybrid microturbine system. In: Proceedings of SolarPACES Conference, Las Vegas, NV; March $4-7$.

[11] Amsbeck, L., Denk, T., Ebert, M., Gertig, C., Heller, P., Herrmann, P., et al., 2010. Test of a solarhybrid microturbine system and evaluation of storage deployment. In: Proceedings of solarPACES Conference, Perpignan, France; September 21-24.

[12] Boerema, N., Morrison, G., Taylor, R., Rosengarten, G., 2013. High temperature solar thermal centralreceiver billboard design. Solar Energy, 97, 356-368.

[13] Rodriguez-Sanchez, M.R., Soria-Verdugo, A., Almendros-Ibanez, J.A., Acosta-Iborra, A., Santana, D., 2014. Thermal design guidelines of solar power towers. Applied Thermal Engineering, 63, 428-438.

[14] Lim, S., Kang, Y., Lee, H., Shin, S., 2014. Design optimization of a tubular solar receiver with a porous medium. Applied Thermal Engineering, 62, 566-572.

[15]Zhang, Q., Li, X., Wang, Z., Chang, C., Liu, H., 2013. Experimental and theoretical analysis of a dynamic test method for molten salt cavity receiver. Renewable Energy, 50, 214-221.

[16] Quero, M., Korzynietz, R., Ebert, M., Jiménez, AA., del Rio, A., Brioso, JA., 2014. Solugas-Operation experience of the first solar hybrid gas turbine system at MW scale. Energy Procedia, 49, 1820-1830.

[17] Li, Q., Guérin de Tourville, N., Yadroitsev, I., Yuan, X., Flamant, G., 2013. Micro-channel pressurizedair solar receiver based on compact heat exchanger concept. Solar Energy, 91, 186-195.

[18] Salomé, A., Chhel, F., Flamant, G., Ferrière, A., Thiery, F., 2013. Control of the flux distribution on a solar tower receiver using an optimized aiming point strategy: Application to THEMIS solar tower. Solar Energy, 94, 352-366.

[19]Fork, D.K., Fitch, J., Ziaei, S., Jetter, R.I., 2012. Life estimation of pressurized-air solar-thermal receiver tubes. Journal of Solar Energy Engineering, 134, 041016. 
[20] Grange, B., Ferriere, A., Bellard, D., Vrinat, M., Couturier, R., Pra, F., et al., 2011. Thermal performances of a high temperature air solar absorber based on compact heat exchanger technology. ASME Journal of Solar Energy Engineering, 133, 031004-1.

[21] Garcia, P., Ferriere, A., Bezian, J.J., 2008. Codes for solar flux calculation dedicated to central receiver system applications: a comparative review. Solar Energy, 82, 189-197.

[22] Grange, B., 2012. Modélisation et dimensionnement d'un récepteur solaire à air pressurisé pour le projet PEGASE. PhD thesis of Université de Perpignan.

[23]Luo, L., Wei, M., Fan, Y., Flamant, G., 2015. Heuristic shape optimization of baffled fluid distributor for uniform flow distribution. Chemical Engineering Science, 123, 542-556.

[24] Wei, M., Fan, Y., Luo, L., Flamant, G., 2015. CFD-based evolutionary algorithm for the realization of target fluid flow distribution among parallel channels. Chemical Engineering Research and Design, 100, 341-352.

[25]Fan, Y., Boichot, R., Goldin, T., Luo, L., 2008. Flow distribution property of the constructal distributor and heat transfer intensification in a mini heat exchanger. AIChE Journal, 54, 2796-2808.

[26] Guo, X., Fan, Y., Luo, L., 2014. Multi-channel heat exchanger-reactor using arborescent distributors: A characterization study of fluid distribution, heat exchange performance and exothermic reaction. Energy, 69, 728-741.

[27] Li, Q., 2012. The optimization of fluid flow and heat transfer in high-temperature pressurized air solar receivers. PhD thesis of Université de Perpignan.

[28]Flesch, R., Stadler, H., Uhlig, R., Pitz-Paal, R., 2014. Numerical analysis of the influence of inclination angle and wind on the heat losses of cavity receivers for solar thermal power towers. Solar Energy, 110 , 427-437.

[29] Yang, S., Tao, W., 1998. Heat transfer, third ed. Higher Education Press, Beijing.

[30] Antonetti, V.W., Whittle, T.D., Simons, R.E., 1993. An approximate thermal contact conductance correlation. ASME Journal of Electronic Packaging, 115, 131-134. 


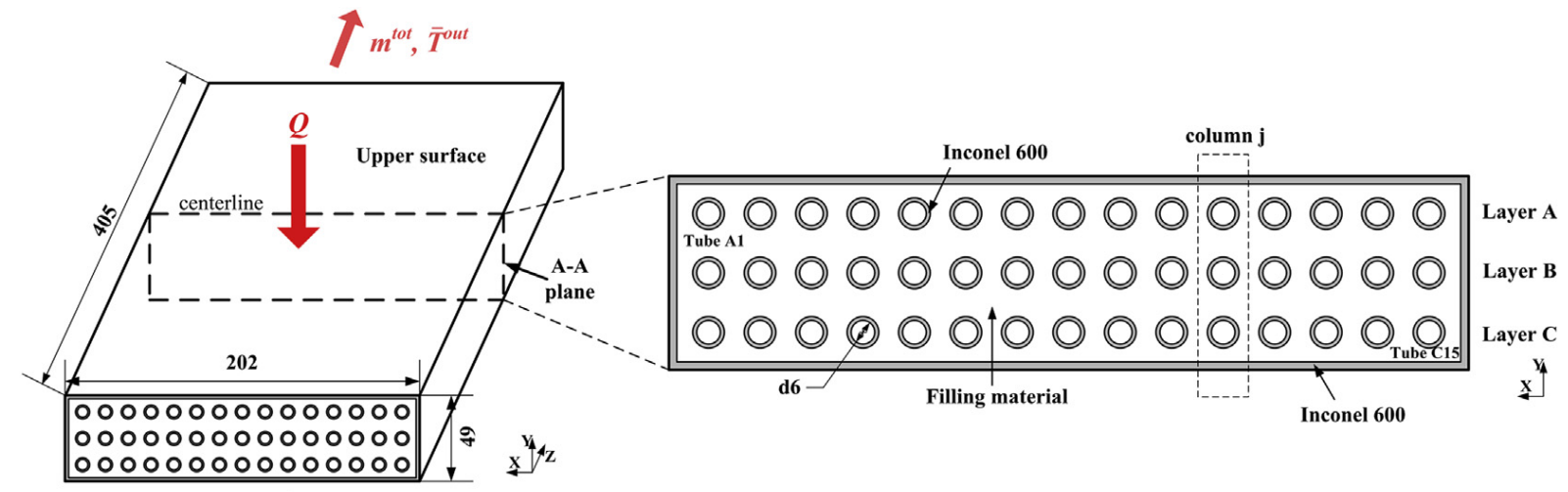

$$
\text { pressurized air } \ m^{t o t}, \bar{T}^{i n}
$$

3 Fig.1. Geometry and dimension of the solar receiver based on tube-in-matrix concept (unit: $\mathrm{mm})$.

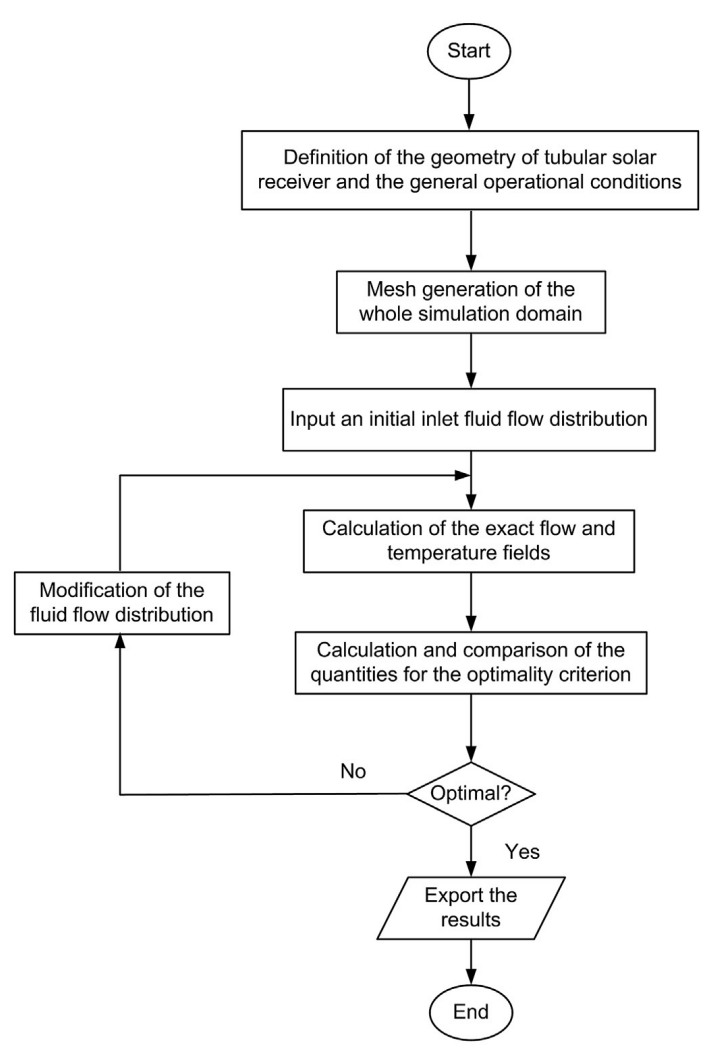

Fig. 2. Flow chart of the evolutionary algorithm. 

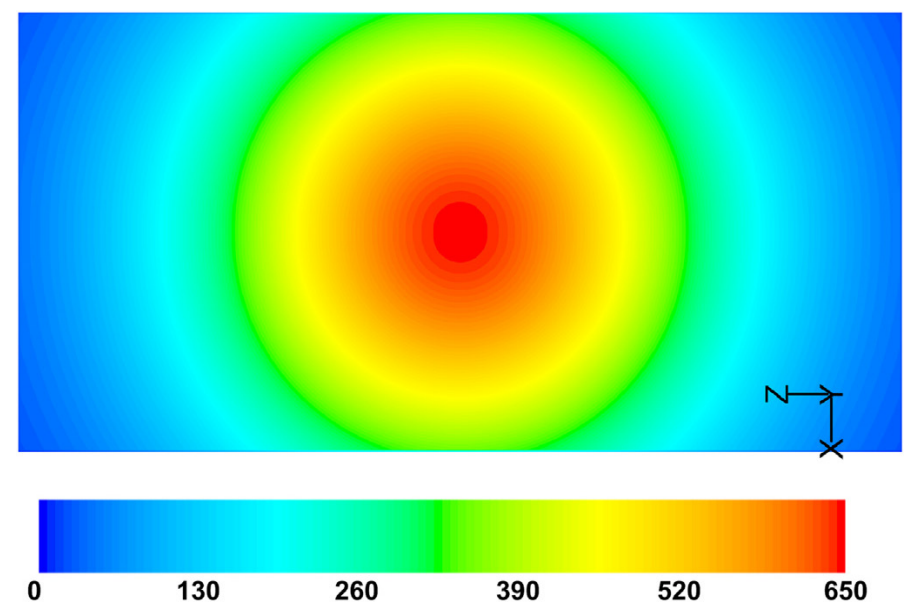

2 Fig. 3. Gaussian net heat flux $\left(\mathrm{kW} \cdot \mathrm{m}^{-2}\right)$ absorbed by the heated surface of the solar receiver.
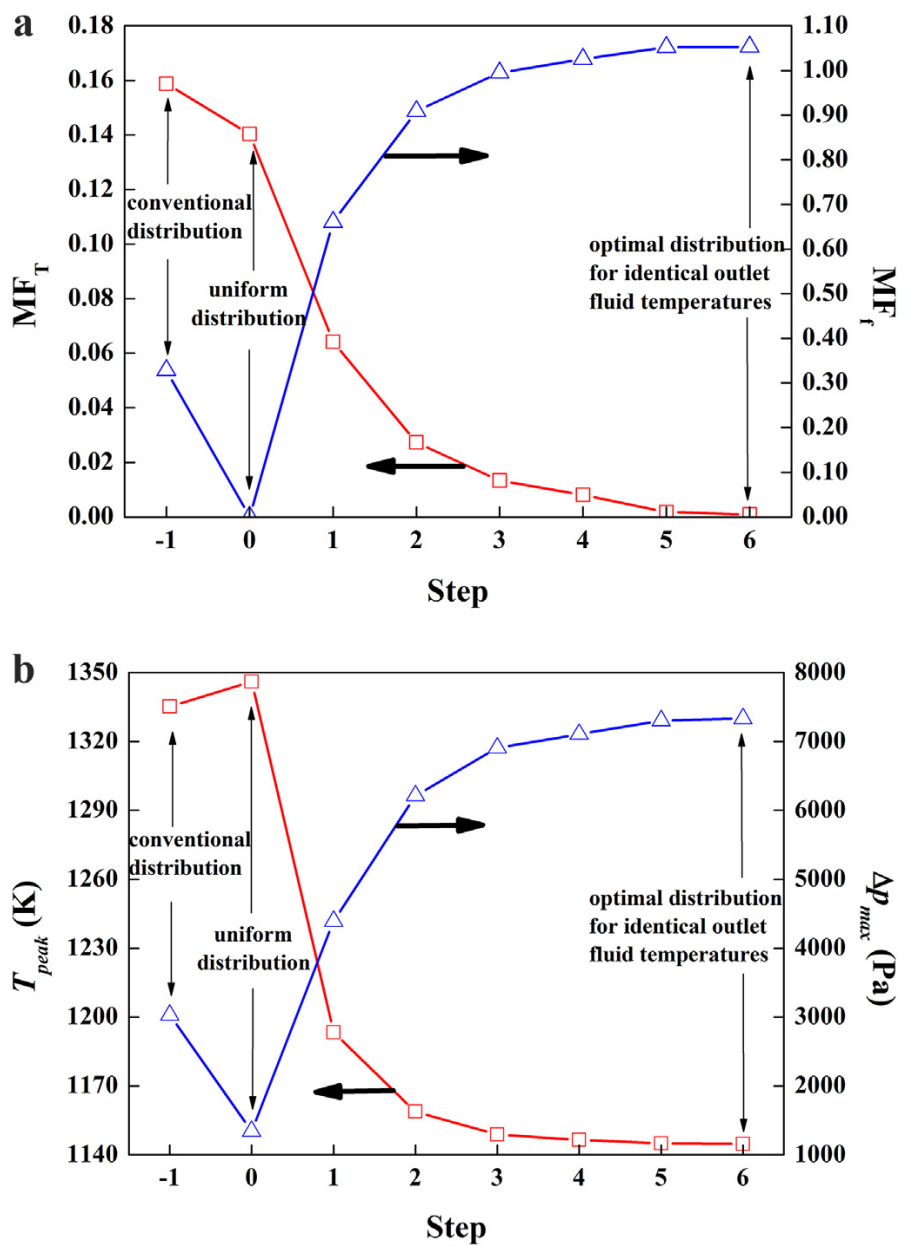

Fig. 4. Evolution of different parameters as a function of optimization step. (a) non-uniformity of outlet fluid temperatures $\left(\mathrm{MF}_{\mathrm{T}}\right)$ and non-uniformity of fluid flow distribution $\left(\mathrm{MF}_{\mathrm{f}}\right)$; $(\mathrm{b})$ surface peak temperature $\left(T_{\text {peak }}\right)$ and maximum pressure drop $\left(\Delta p_{\max }\right)$. 

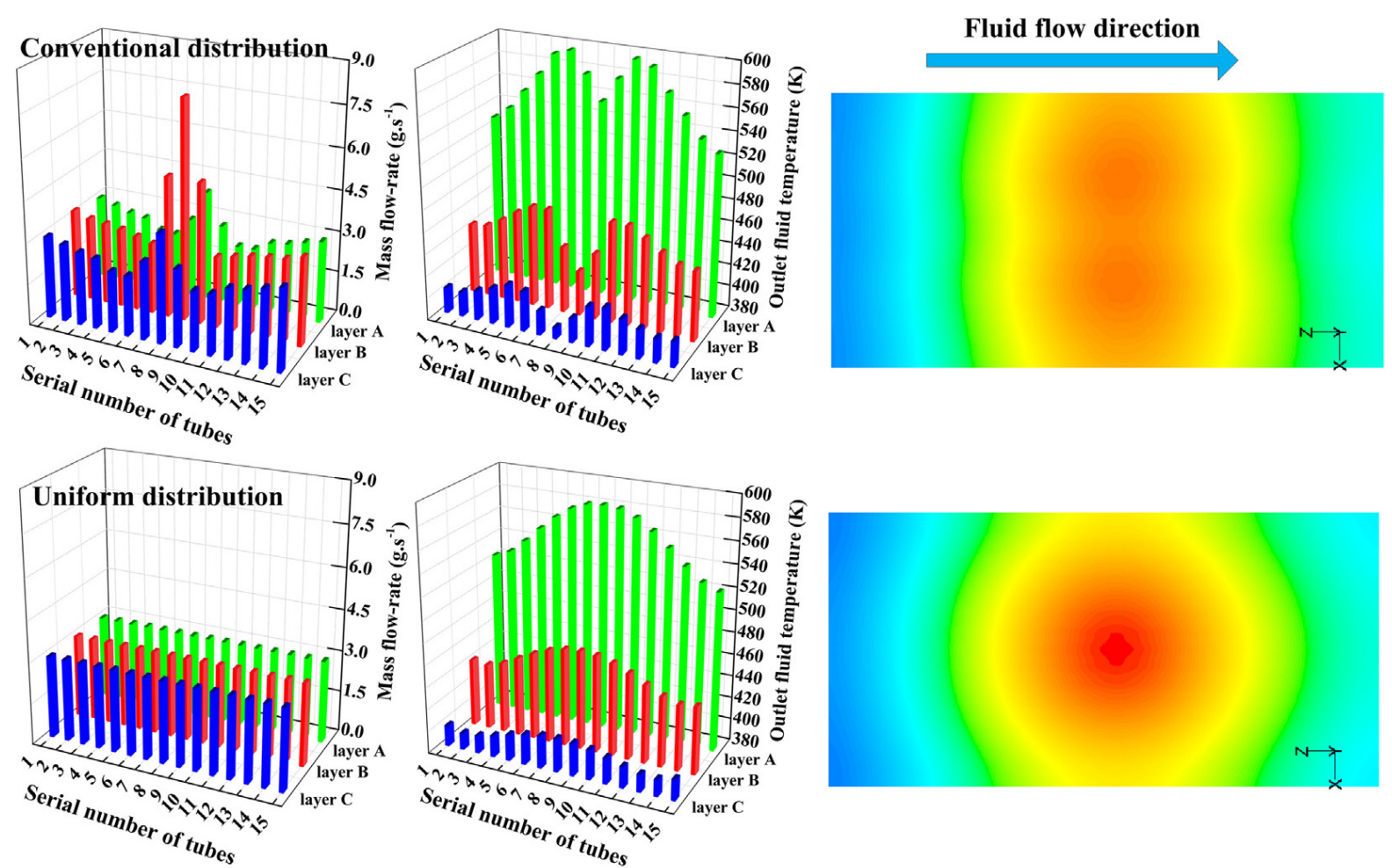

Optimal distribution for identical

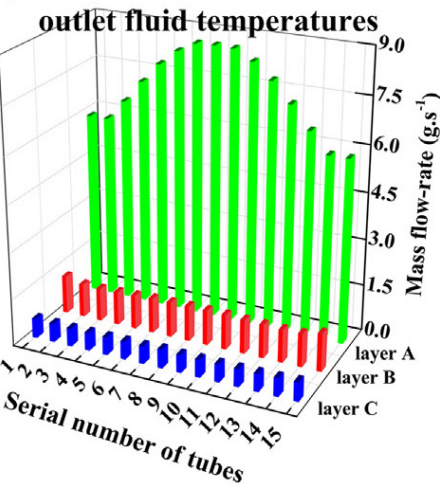

(a)

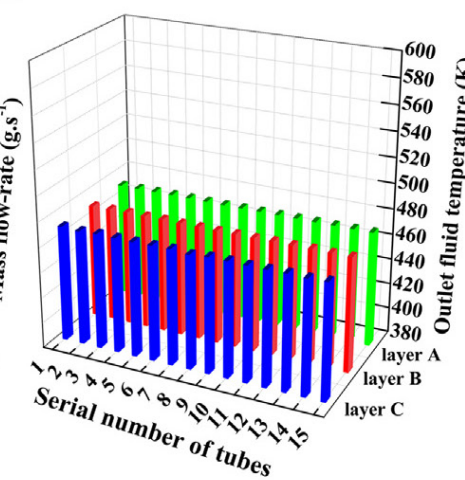

(b)

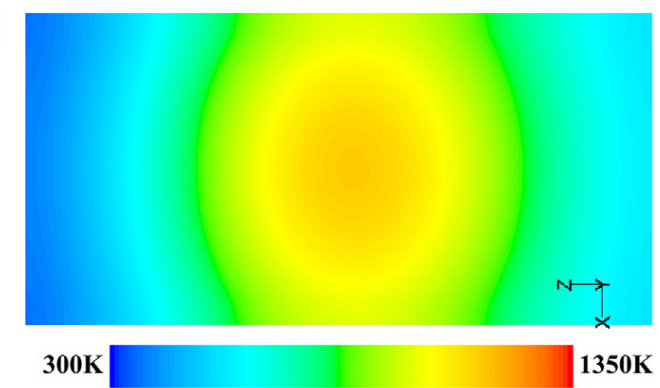

(c)

Fig. 5. Fluid flow and thermal characteristics under three different fluid flow distribution cases. (a) fluid flow distribution; (b) outlet fluid temperature distribution; (c) temperature field on the heated surface of solar receiver. 


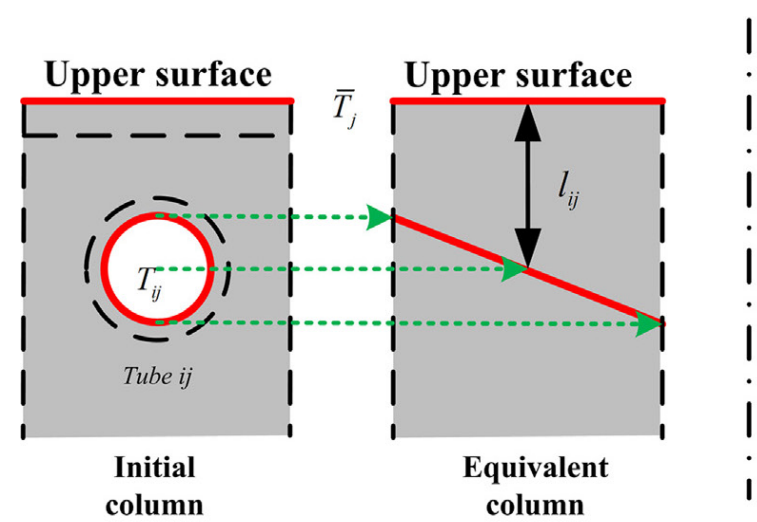

(a)

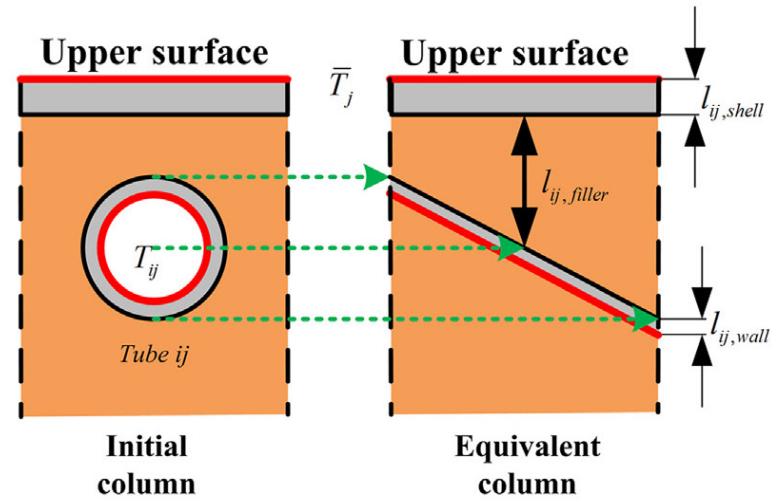

(b)

Fig. 6. Simplified heat transfer model for the A-A plane: (a) single material; (b) shell and filler.

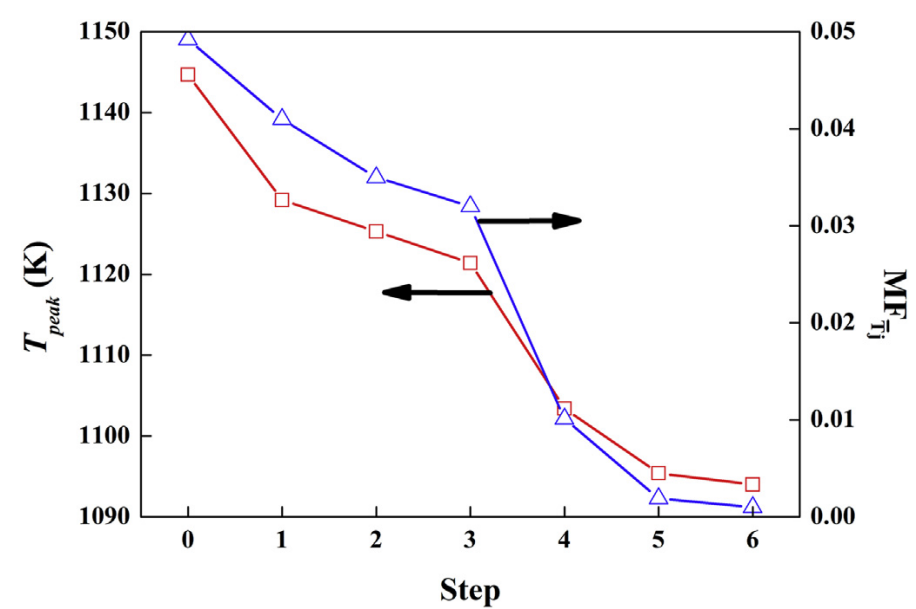

Fig. 7. Evolution of surface peak temperature $\left(T_{\text {peak }}\right)$ and non-uniformity of $\bar{T}_{j}\left(\mathrm{MF}_{\overline{\mathrm{T}}_{\mathrm{j}}}\right)$ as a function of optimization step. 

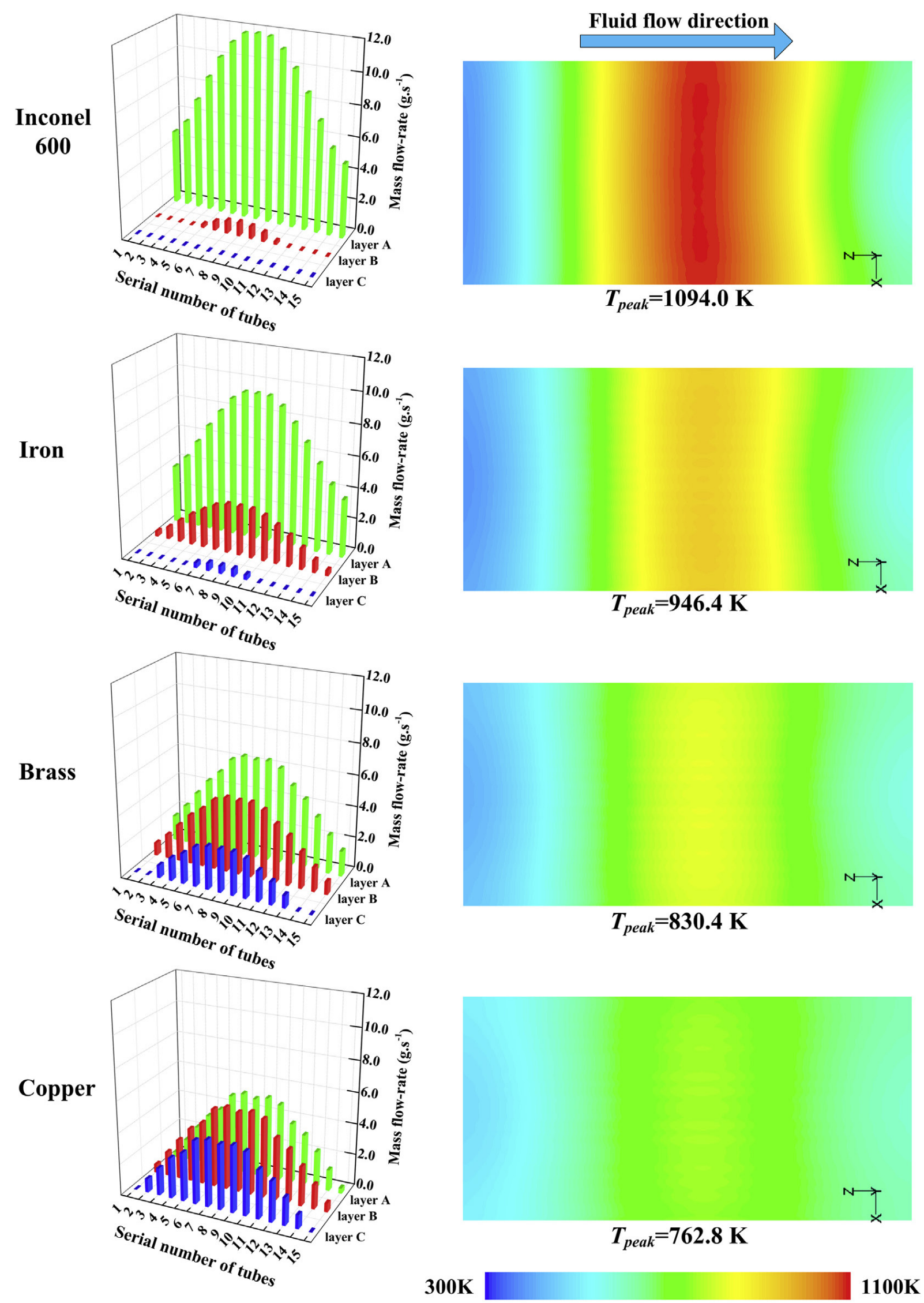

(a)

(b)

Fig. 8. Effects of different filling materials on the optimal fluid distribution (a) and the corresponding temperature field of the heated surface (b). 


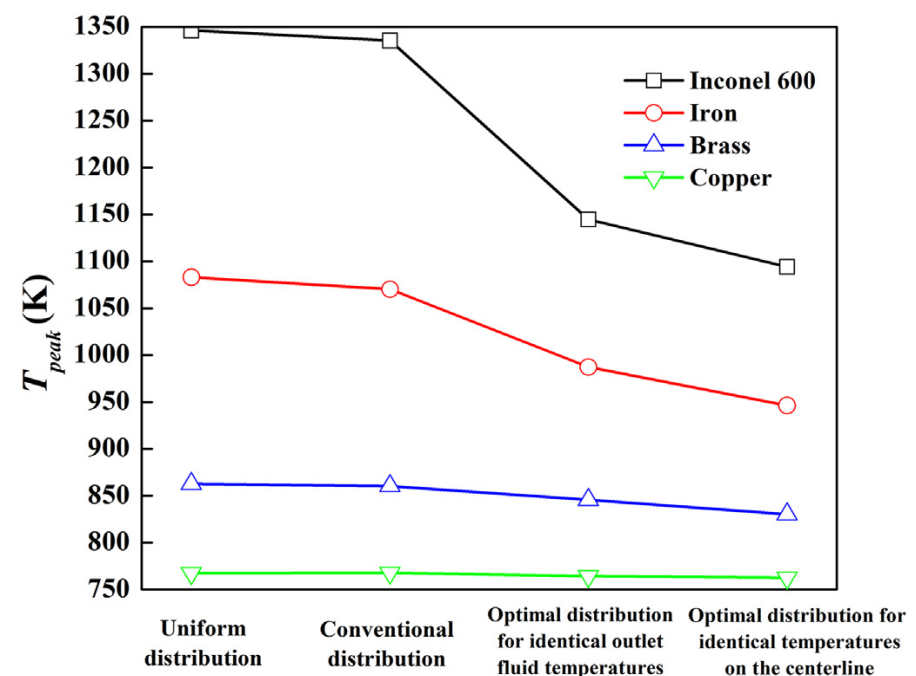

Fig. 9. Peak temperature reduction for different filling materials. 
$\mathbf{a}$
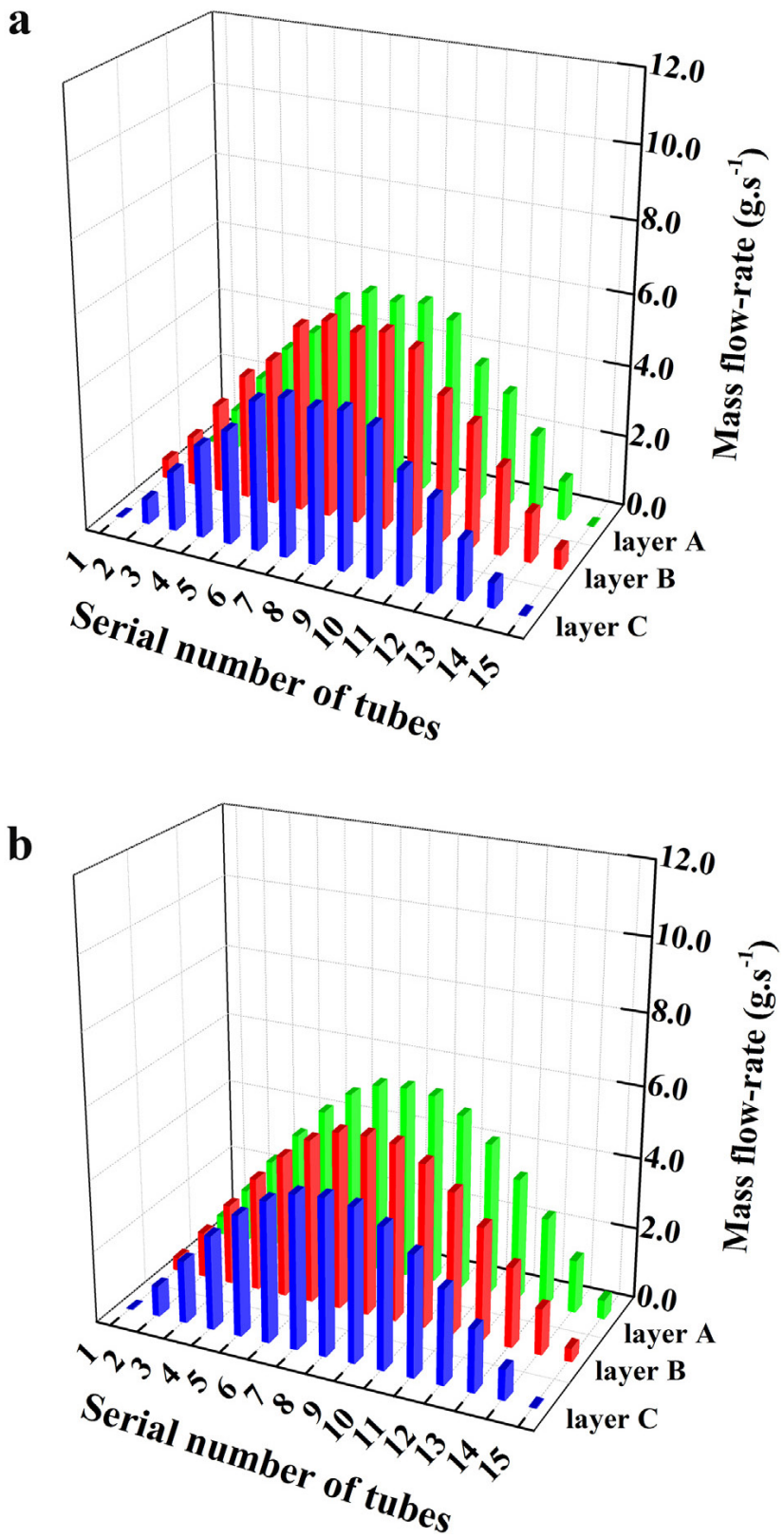

2

Fig. 10. Optimal fluid flow distribution considering thermal contact resistances (copper as filling material). (a) $1 / h_{c}=1 \times 10^{-5} \mathrm{~m}^{2} \cdot \mathrm{K} \cdot \mathrm{W}^{-1}$; (b) $1 / h_{c}=1 \times 10^{-4} \mathrm{~m}^{2} \cdot \mathrm{K} \cdot \mathrm{W}^{-1}$.

4 


\section{$1 \quad$ List of tables}

2 Table 1. Some recent studies on tubular solar receiver (N: numerical study; E: experimental study).

\begin{tabular}{|c|c|c|c|c|c|c|}
\hline Study & $\begin{array}{l}\text { Study } \\
\text { type }\end{array}$ & Geometry \& material & $\begin{array}{l}\text { Heat } \\
\text { transfer } \\
\text { fluid }\end{array}$ & Inlet working and test conditions & $\begin{array}{l}\text { Outlet } \\
\text { temperature } \\
\text { /thermal } \\
\text { efficiency }\end{array}$ & Remarks \\
\hline $\begin{array}{l}\text { Heller et al. } \\
\quad(2006)\end{array}$ & E & $\begin{array}{l}\text { SOLGATE low temperature receiver } \\
\text { module: number of tubes }=16, \text { multi- } \\
\text { tube coil attached to a hexagonal } \\
\text { secondary concentrator }\end{array}$ & $\begin{array}{l}\text { Pressurized } \\
\text { air }\end{array}$ & $\begin{array}{c}T^{i n}=300^{\circ} \mathrm{C} ; \\
\text { average irradiance }=770 \mathrm{~kW} \cdot \mathrm{m}^{-2} \\
45 \text { heliostats; } \underset{\mathrm{air} \text { mass flow }=1.4-1.6}{\mathrm{~kg} \cdot \mathrm{s}^{-1}}\end{array}$ & $\begin{array}{c}960^{\circ} \mathrm{C} / \sim 70 \% \\
\text { (overall SOLGATE) }\end{array}$ & $\begin{array}{l}\text { This low temperature receiver module design results in an } \\
\text { average temperature increase of about } 200 \mathrm{~K} \text { for air and an } \\
\text { associated pressure drop of } 100 \mathrm{mbar} \text {. The maximum tube } \\
\text { surface temperature is } 950{ }^{\circ} \mathrm{C} \text { at a module air outlet } \\
\text { temperature of } 550^{\circ} \mathrm{C} \text {. }\end{array}$ \\
\hline $\begin{array}{l}\text { Amsbeck et al. } \\
(2008 ; 2010)\end{array}$ & $\mathrm{N}, \mathrm{E}$ & $\begin{array}{l}\text { SOLHYCO-receiver: length }=2.5 \mathrm{~m} \\
\text { number of tubes }=40, \text { nickel based } \\
\text { super alloy Inconel } 600\end{array}$ & Air & $\begin{array}{l}T^{i n}=600^{\circ} \mathrm{C} \text {; input power }=230-290 \mathrm{~kW} \text {; } \\
\text { open aperture and with quartz window; } \\
38-46 \text { heliostats; mass flow }=0.8 \mathrm{~kg} \cdot \mathrm{s}^{-1} \\
(\mathrm{~N}), 0.51 \mathrm{~kg} \cdot \mathrm{s}^{-1}(\mathrm{E})\end{array}$ & $\begin{array}{l}800^{\circ} \mathrm{C} / \sim 70 \%(\mathrm{~N}) \\
\sim 40 \%(\mathrm{E})\end{array}$ & $\begin{array}{l}\text { The design outlet fluid temperature is reached in both open } \\
\text { aperture and quartz window configuration. The low efficiency } \\
\text { in the experiments is due to heat loss through the cavity walls } \\
\text { and lower-than-expected mass flow. }\end{array}$ \\
\hline $\begin{array}{l}\text { Boerema et al. } \\
\quad(2013)\end{array}$ & $\mathrm{N}$ & $\begin{array}{l}\text { Single-diameter receiver: outer } \\
\text { diameter }=25.4 \mathrm{~mm} \text {, length }=1.5 \mathrm{~m} \text {, } \\
\text { wall thickness }=1 \mathrm{~mm} ; \\
\text { Ideal flow receiver; } \\
\text { Multi-diameter receiver; } \\
\text { Multi-pass receiver }\end{array}$ & $\begin{array}{l}\text { Molten } \\
\text { Sodium }\end{array}$ & $\begin{array}{l}\qquad T^{i n}=200^{\circ} \mathrm{C} \text {; } \\
\text { Centered heat flux distribution, off- } \\
\text { centered flux distribution and } \\
\text { alternative flux distribution, average } \\
\quad \text { irradiance }=737 \mathrm{~kW} \cdot \mathrm{m}^{-2}\end{array}$ & $570{ }^{\circ} \mathrm{C} / \sim 90 \%$ & $\begin{array}{l}\text { The ideal flow receiver has the lowest surface peak } \\
\text { temperature. The multi-pass receiver out-performs the other } \\
\text { designs by reducing the risk from irradiance changes. }\end{array}$ \\
\hline $\begin{array}{l}\text { Rodriguez- } \\
\text { Sanchez et al. } \\
\quad(2014)\end{array}$ & $\mathrm{N}$ & $\begin{array}{c}\text { Receiver height }=10.5 \mathrm{~m} \text {; Receiver } \\
\text { diameter }=8.4 \mathrm{~m} \text {; total number of } \\
\text { panels }=18 ; \text { number of tubes per } \\
\text { panel }=22 ; \\
\text { external diameter of outer tube }=60.3 \\
\text { mm; } \\
\text { external diameter of inner tube }=52 \\
\mathrm{~mm}\end{array}$ & Molten salt & $\begin{array}{l}T^{i n}=290^{\circ} \mathrm{C} \\
\text { Average heat flux }=800 \mathrm{~kW} \cdot \mathrm{m}^{-2} \\
\text { maximum heat flux }=1200 \mathrm{~kW} \cdot \mathrm{m}^{-2} \\
\text { Total mass flow }=290 \mathrm{~kg} \cdot \mathrm{s}^{-1}\end{array}$ & $565^{\circ} \mathrm{C} / \sim 75 \%$ & $\begin{array}{l}\text { The surface peak temperature can be reduced by } 100{ }^{\circ} \mathrm{C} \text { and } \\
\text { the thermal efficiency increases by } 2 \% \text { due to the bayonet } \\
\text { receiver. } \\
\text { The corrosion rate and salt decomposition ratio have } \\
\text { decreased. }\end{array}$ \\
\hline $\begin{array}{l}\text { Lim et al. } \\
\text { (2014) }\end{array}$ & $\mathrm{N}, \mathrm{E}$ & $\begin{array}{l}\text { Cylindrical shell: length= }=259 \mathrm{~mm} \text {, } \\
\text { diameter }=114 \mathrm{~mm} ; \\
\text { Inlet pipes: diameter }=15.8 \mathrm{~mm} \text { and } \\
9.6 \mathrm{~mm} \text {, number of pipes }=4-7 \text {; } \\
\text { Outlet pipes: diameter }=25.4 \mathrm{~mm} \text {; } \\
\text { Stainless steel AISI304 }\end{array}$ & Air & $\begin{array}{l}T^{i n}=300^{\circ} \mathrm{C} ; \\
\text { Heat flux }=1000 \mathrm{~kW} \cdot \mathrm{m}^{-2} ; \text { mass flow } \\
\text { rate }=0.0128 \mathrm{~kg} \cdot \mathrm{s}^{-1}\end{array}$ & $736^{\circ} \mathrm{C} / \sim 90 \%$ & $\begin{array}{l}\text { Tubular solar receiver filled with a porous medium can } \\
\text { enhance heat transfer efficiency and reduce the surface peak } \\
\text { temperature by } 75 \mathrm{~K} \text {. }\end{array}$ \\
\hline $\begin{array}{l}\text { Zhang et al. } \\
\text { (2013) }\end{array}$ & $\mathrm{N}, \mathrm{E}$ & $\begin{array}{l}\text { Tube: outside diameter }=14 \mathrm{~mm} \text {, wall } \\
\text { thickness }=1.4 \mathrm{~mm} \text {, number of } \\
\text { tubes }=28, \text { stainless steel }\end{array}$ & Molten salt & $\begin{array}{l}\quad T^{i n}=180-322{ }^{\circ} \mathrm{C} \\
\text { Volume flow rate }=7.61 \cdot \mathrm{min}^{-1} \\
\text { Input power }=37.68-118.91 \mathrm{~kW}\end{array}$ & $193-415^{\circ} \mathrm{C} /-$ & $\begin{array}{l}\text { The theoretical analysis predicted the outlet temperature with } \\
\text { maximum difference of } 66.32{ }^{\circ} \mathrm{C} \text { and relative error of } \\
14.69 \% \text {; Prediction was not accurate when the input power } \\
\text { varied rapidly. }\end{array}$ \\
\hline $\begin{array}{l}\text { Quero et al. } \\
\text { (2014) }\end{array}$ & E & $\begin{array}{l}\text { SOLUGAS solar receiver: height }=65 \\
\text { m, inclination angle }=35^{\circ}\end{array}$ & $\begin{array}{l}\text { Pressurized } \\
\text { air }\end{array}$ & $\begin{array}{l}\quad T^{i n}=300{ }^{\circ} \mathrm{C} ; \\
\text { Heat flux }=400-1000 \mathrm{~kW} \cdot \mathrm{m}^{-2} ; \text { mass }\end{array}$ & $800^{\circ} \mathrm{C} /-$ & $\begin{array}{l}\text { The pressurized air can be heated up to } 800{ }^{\circ} \mathrm{C} \text { and further } \\
\text { heated with natural gas to reach the working temperature of }\end{array}$ \\
\hline
\end{tabular}


Tubes: number $=170$, fine nickel

$$
\text { based alloy }
$$

flow rate $=3.5-5.75 \mathrm{~kg} \cdot \mathrm{s}^{-1} ; 69$ heliostats,

$$
\text { reflective area of each }=121 \mathrm{~m}^{2}
$$

Solar receiver: surface area $=30$

$$
625 \text { powder; }
$$

Li et al. (2013)

Channel: 12 parallel micro-channels, width $=1 \mathrm{~mm}$, height $=3 \mathrm{~mm}$, rectangular ribs on the top of
Heat flux $=170-470 \mathrm{~kW} \cdot \mathrm{m}^{-2}$; mass flow rate $=0.431-0.862 \mathrm{~g} \cdot \mathrm{s}^{-1} ;$ pressure: $2-6$
$T^{i n}=300{ }^{\circ} \mathrm{C}$; $\mathrm{mm} \times 30 \mathrm{~mm}$, fabricated from Inconel

$1150^{\circ} \mathrm{C}$$$
\text { channels; }
$$

$400-660{ }^{\circ} \mathrm{C} /-$

Micro-channel design can meet the expected demand on temperature elevation of air in CSP receivers.

$$
\text { width }=1 \mathrm{~mm}
$$


1 Table 2. Physical properties of fluid and solid used for simulations (Li, 2012).

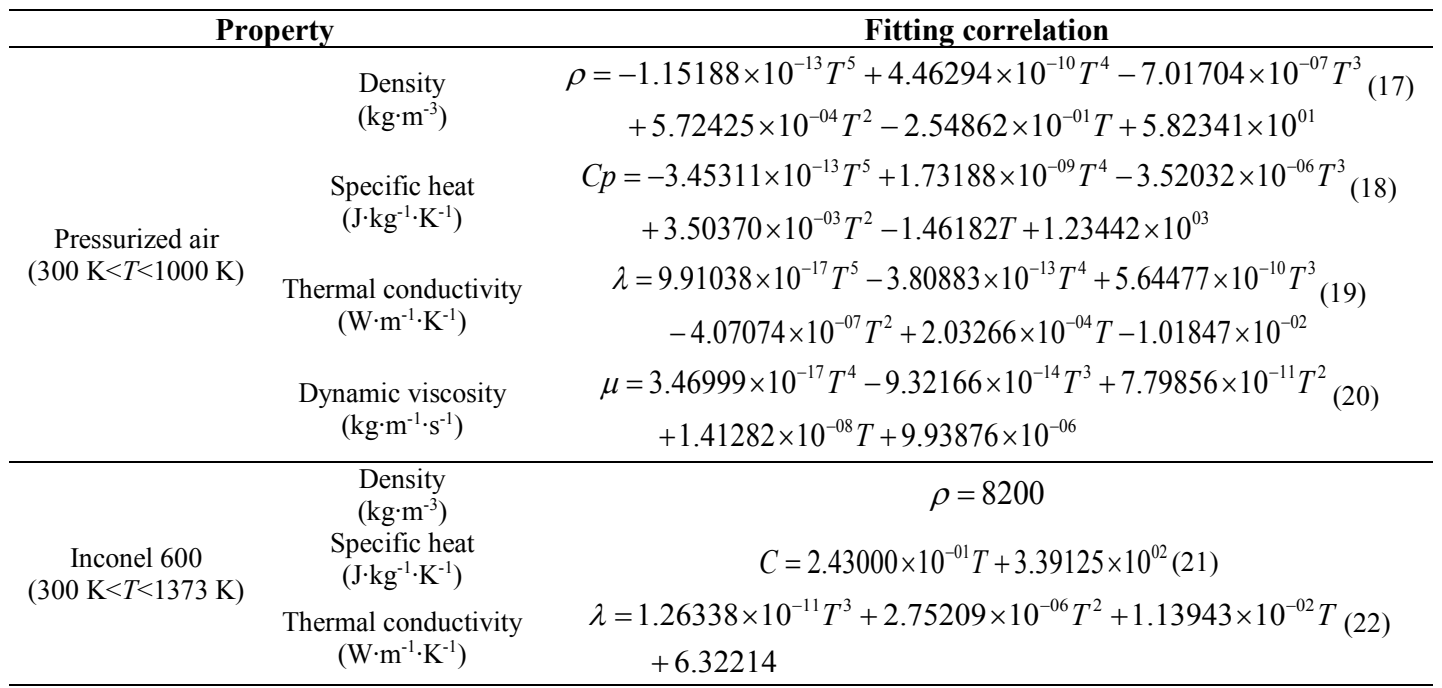

2

3 Table 3. Physical proprieties of different filling materials within the tested temperature (K)

4 range (Yang and Tao, 1998; Li, 2012).

\begin{tabular}{|c|c|c|c|}
\hline Material & $\rho\left(\mathbf{k g} \cdot \mathbf{m}^{-3}\right)$ & $\lambda\left(\mathbf{W} \cdot \mathbf{m}^{-1} \cdot \mathbf{K}^{-1}\right)$ & Range of $\lambda\left(\mathbf{W} \cdot \mathbf{m}^{-1} \cdot \mathbf{K}^{-1}\right)$ \\
\hline Copper & 8930 & $-0.056 T+415.5$ & 399-371 (300 K-800 K) \\
\hline Brass & 8440 & $\begin{array}{l}6.486 \times 10^{-07} T^{3}-1.321 \times 10^{-03} T^{2}(33) \\
+8.895 \times 10^{-01} T-5.130 \times 10^{01}\end{array}$ & $114-152(300 \mathrm{~K}-900 \mathrm{~K})$ \\
\hline Iron & 7870 & $\begin{array}{l}-6.183 \times 10^{-08} T^{3}+1.644 \times 10^{-04} T^{2}(34) \\
-1.946 \times 10^{-01} T+1.254 \times 10^{02}\end{array}$ & $80.1-28.0(300 \mathrm{~K}-1100 \mathrm{~K})$ \\
\hline Inconel 600 & 8200 & $\begin{array}{l}1.26338 \times 10^{-11} T^{3}+2.75209 \times 10^{-06} T^{2}(22) \\
+1.13943 \times 10^{-02} T+6.32214\end{array}$ & 9.99-27.2 (300 K-1373 K) \\
\hline
\end{tabular}

5

6 Table 4. $T_{\text {peak }}$ under different thermal contact resistances

\begin{tabular}{cccc}
\hline Shape of fluid flow distribution & $1 / h_{c}=0$ & $1 / h_{c}=1 \times 10^{-5}$ & $1 / h_{c}=1 \times 10^{-4}$ \\
& $\mathrm{~m}^{2} \cdot \mathrm{K}^{-} \mathrm{W}^{-1}$ & $\mathrm{~m} \cdot \mathrm{K}^{2} \cdot \mathrm{W}^{-1}$ & $\mathrm{~m}^{2} \cdot \mathrm{K}^{-1}$ \\
\hline Uniform & $767.6 \mathrm{~K}$ & $771.3 \mathrm{~K}$ & $829.4 \mathrm{~K}$ \\
Optimal under OC-II & $762.8 \mathrm{~K}$ & $766.4 \mathrm{~K}$ & $821.4 \mathrm{~K}$ \\
\hline
\end{tabular}

